\title{
Platelets stimulated by IgG-coated surfaces bind and activate neutrophils through a selectin-dependent pathway
}

\author{
Jonas Wetterö, Pentti Tengvall and Torbjörn Bengtson
}

\section{Linköping University Post Print}

N.B.: When citing this work, cite the original article.

Original Publication:

Jonas Wetterö, Pentti Tengvall and Torbjörn Bengtson, Platelets stimulated by IgG-coated surfaces bind and activate neutrophils through a selectin-dependent pathway, 2003, Biomaterials, (24), 9, 1559-1573.

http://dx.doi.org/10.1016/S0142-9612(02)00543-4

Copyright: Elsevier http://www.elsevier.com/

Postprint available at: Linköping University Electronic Press http://urn.kb.se/resolve?urn=urn:nbn:se:liu:diva-26376 


\title{
Platelets stimulated by IgG-coated surfaces bind and activate neutrophils through a selectin-dependent pathway
}

\author{
Jonas Wetterö $^{\mathrm{a}, \mathrm{b}} *$, Pentti Tengvall ${ }^{\mathrm{a}}$ and Torbjörn Bengtsson ${ }^{\mathrm{b}}$ \\ ${ }^{a}$ Division of Applied Physics, Department of Physics and Measurement Technology, Biology and \\ Chemistry, Linköping University, SE-581 83 Linköping, Sweden \\ ${ }^{b}$ Division of Medical Microbiology, Department of Molecular and Clinical Medicine, Faculty of Health \\ Sciences, Linköping University, SE-581 85 Linköping, Sweden
}

*Corresponding author.

Fax: +4613 137568, phone: +4613282755

E-mail address: jonwe@ifm.liu.se

Key words: respiratory burst, aggregation, biomaterial, integrin, actin

Running Title: IgG-stimulated platelets activate neutrophils 


\begin{abstract}
Blood platelets bind rapidly to foreign surfaces and interact with adsorbed proteins and neutrophil granulocytes. We demonstrate by use of luminol-amplified chemiluminescence under stirred and nonstirred conditions that platelets at IgG-coated surfaces amplify the neutrophil extracellular release of reactive oxygen species (ROS). The neutrophil response involved tyrosine phosphorylation, but was only in part induced by neutrophil $\mathrm{F}_{\mathrm{c} \gamma}$-receptor stimulation. The platelet mediated effects were contact-dependent since the respiratory burst was inhibited when the IgG-stimulated platelets were removed by filtration, but not when they were fixed in paraformaldehyde. Bodipyphallacidin-staining of filamentous actin (F-actin) revealed that an actin-dependent platelet adhesion supported the subsequent adhesion and spreading of neutrophils. The neutrophil ROS-response was lowered when the interaction between platelet P-selectin (CD62P) and neutrophil P-selectin glycoprotein ligand-1 (PSGL-1 or CD162) was inhibited. The blocking of L-selectin (CD62L) or blocking of the interaction between platelet glycoprotein (Gp) IIb/IIIa and neutrophil complement receptor 3 (CR3) showed no effect. We conclude that platelet activation on immobilized IgG trigger a contact-dependent "frustrated" phagocytosis by neutrophils, associated with a release of toxic ROS.
\end{abstract}




\section{INTRODUCTION}

The use of medical devices is rapidly increasing as a consequence of technological progress and the need to improve the health of an aging population. When artificial surfaces become exposed to blood, e.g. during implantation of cardiovascular devices such as heart valves, pacemakers and vascular grafts, an uncontrolled regulation of hemostatic and inflammatory processes may lead to thrombus formation and release of toxic substances from activated leukocytes. Although the inflammatory reaction is a vital part of the body's response against trauma, an exaggerated or prolonged inflammation may be harmful to the host. Most artificial materials intended for use in indwelling medical devices or in direct blood-contacting applications (referred to as biomaterials) appear non-toxic, with relatively well-known surface chemistry, and could therefore be expected to display a low biological activity. Clinical experience reveals, however, that biomaterials trigger both acute and chronic inflammatory responses (reviewed in [1]), most likely due to a general incompatibility between biomaterials and tissue. Inflammation triggered by an artificial surface is not necessarily a bad event but undesirable in most blood contacting applications.

Plasma proteins adsorb before cells adhere to artificial surfaces. The composition of the adsorbed protein layer depends then on the surface physical and chemical properties and may vary over time [2]. Two abundant plasma proteins, albumin and immunoglobulin $\mathrm{G}(\mathrm{IgG})$, are frequently detected after short contact time with body fluids [2-4]. Native surface-bound albumin suppresses the early inflammatory response, but adsorbed $\operatorname{IgG}$ is a potent initiator and activator of both humoral and cellular parts of the acute host response. However, the role of IgG for the initiation of inflammatory and aggregatory responses at interfaces is still not well understood, although both neutrophils and platelets express $F_{c}$-receptors ( $\mathrm{F}_{\mathrm{c \gamma}} \mathrm{RII} / \mathrm{CD} 32$ and $\mathrm{F}_{\mathrm{c \gamma}} \mathrm{RIII} / \mathrm{CD} 16$ on neutrophils and $\mathrm{Fc}_{\gamma} \mathrm{RII} / \mathrm{CD} 32$ on platelets).

Upon recognition of invading bacteria or other foreign particles, the neutrophil granulocyte activates a number of killing mechanisms including the generation of nitric oxide, superoxide, hypochlorite and other products of activated oxygen and nitrogen metabolism, as well as release of proteolytic enzymes (reviewed in [5-7]). When encountering an artificial surface, the neutrophil tries to engulf the entire device

("frustrated" phagocytosis). The associated leakage of toxic enzymes and oxygen metabolites may then 
damage the biomaterial and surrounding tissues, and potentially increase the vulnerability to biomaterial related infection [8].

Platelets are specialized for hemostasis and wound healing. When exposed to subendothelial structures (e.g. collagen and von Willebrand factor) or artificial surfaces they respond rapidly by adhesion, spreading, aggregation and secretion, with the intention to minimize blood loss. The reactivity is also a powerful means to initiate and regulate the early phase of inflammation and wound healing (reviewed by Marcus [9]). Platelet binding to immune complexes may precede and augment neutrophil localization with subsequent neutrophil-mediated tissue damage.

Recent observations suggest that platelets deposited at thrombosis and vascular injury sites, for example associated with cardiovascular intervention, may serve as surrogates for endothelial cells in their ability to promote the adhesion and accumulation of circulating neutrophils [10]. The process involves sequential action of P-selectin (CD62P, GMP-140 or PADGEM) and $\beta_{2}$-integrins (CD18) [11]. P-selectin interacts with a sialylated carbohydrate backbone by the leukocyte glycoproteins P-selectin glycoprotein ligand-1 (PSGL-1 or CD162) [12] and possibly L-selectin (CD62L) [13]. The selectin mediated tethering and rolling mechanisms of neutrophils and platelets are highly shear dependent. Leukocyte $\beta_{2}$-integrins may bind directly to ICAM-2, via fibrinogen bridging indirectly to GpIIb/IIIa (CD41/CD61 or $\alpha \mathrm{IIb} / \mathrm{III}$ ) [14] or possibly to GpIba [15]. It is generally considered that an integrin-mediated firm adhesion of neutrophils to endothelial cells or platelets require a prior selectin-dependent interaction. We have recently found that the presence of adhering platelets markedly enhance both the random and the chemotactic transmigration of neutrophils, and that these effects are mediated by P-selectin and associated with increased expression of complement receptor 3 (CR3, CD18/CD11b, Mac-1 or $\alpha_{M} \beta_{2}$ ) [16]. Furthermore, platelets enhance the $\mathrm{F}_{\mathrm{cr}}$-receptor mediated phagocytosis and respiratory burst in neutrophils [17]. Consequently, activated platelets may play an important role for the development of biomaterial-associated inflammatory disorders by promoting the accumulation and emigration of neutrophils and by stimulation of their bactericidal systems. 
In this study, we try to elucidate the intercellular mechanisms involved in platelet-neutrophil interaction on IgG-coated artificial surfaces. 


\section{MATERIALS AND METHODS}

\subsection{Reagents and buffers}

All reagents were of analytical grade and delivered from Sigma Chemical Co. (St. Louis, MO) unless otherwise stated. The buffers were phosphate-buffered saline (PBS; $10 \mathrm{mM}$ sodium hydrogen phosphate, $10 \mathrm{mM}$ potassium dihydrogen phosphate and $0.15 \mathrm{M}$ sodium chloride, $\mathrm{pH}$ 7.3), and KrebsRinger phosphate buffer supplemented with $10 \mathrm{mM}$ glucose, $1.5 \mathrm{mM} \mathrm{MgSO}_{4}$ and $1.1 \mathrm{mM} \mathrm{CaCl}_{2}(\mathrm{pH} 7.3$; $\mathrm{KRG).} \mathrm{KRG}$ was also prepared without the addition of $\mathrm{CaCl}_{2}$.

\subsection{Isolation of neutrophils and platelets}

Peripheral blood was drawn daily from apparently healthy non-medicated volunteers at Linköping University Hospital and was anti-coagulated with $5 \mathrm{IU} / \mathrm{mL}$ heparin. Neutrophil granulocytes (neutrophils) and platelets were isolated from the same donor during each experiment. Blood and blood cells were gently handled using plastic utensils. Calcium was excluded in buffers during blood cell separations. Extracellular calcium was adjusted to $1 \mathrm{mM}$ during pre-warming of the cells to $37^{\circ} \mathrm{C}$ immediately before each experiment.

The neutrophils were prepared essentially according to the methodology pioneered by Böyum [18] and later optimized by others [19]. A density separation medium was prepared by careful layering of one part of Lymphoprep ${ }^{\mathrm{TM}}$ over four parts of Polymorphprep ${ }^{\mathrm{TM}}$ (Axis-Shield PoC AS, Oslo, Norway). Whole blood was layered on an equal volume of separation liquid and the tubes centrifuged in a swing-out rotor for $40 \mathrm{~min}(480 \mathrm{x} g$, room temperature), yielding an upper band containing mononuclear cells, a middle band containing neutrophils and a pellet of red blood cells. The neutrophils were harvested and the separation liquid removed by dilution in PBS and another centrifugation for $10 \mathrm{~min}$ at $480 \mathrm{x} \mathrm{g}$. The remaining erythrocyte contamination was lysed by 35 seconds of exposure to ice-cold distilled water, followed by washing of the cells twice in KRG $\left(200 \mathrm{x} g\right.$ at $\left.4^{\circ} \mathrm{C}\right)$. The neutrophils were counted in a Coulter Counter ZM Channelyser 256 (Coulter-Electronics Ltd., Luton, U.K.) and stored on ice. The platelet contamination was less than 0.1 platelet per neutrophil. 
Platelets were prepared at room temperature as described by Bengtsson and Grenegård [20]. Platelet rich plasma was collected after centrifugation at $220 \mathrm{x} g$ for $20 \mathrm{~min}$ of whole blood mixed with one sixth of an acid-citrate-dextrose solution ( $85 \mathrm{mM}$ sodium citrate, $71 \mathrm{mM}$ citric acid and $111 \mathrm{mM}$ glucose). The cells were pelleted by centrifugation of the platelet rich plasma at $480 \mathrm{x} g$ for $20 \mathrm{~min}$. The plasma was discarded and platelets gently washed and resuspended in KRG. The cell density was determined using a Bürker chamber. Morphological studies showed discoid, solitary platelets displaying no signs of activation due to the preparation procedure. The contamination of other blood cells was negligible.

Non-viable platelets were obtained by fixation for $30 \mathrm{~min}$ in $4 \%$ paraformaldehyde in PBS. The fixed platelets were washed three times by centrifugation for $2 \mathrm{~min}$ at $9000 \mathrm{x} g$ at room temperature and resuspended in KRG. Viable platelet fractions were cleared of cellular components and debris by sterile filtration through low protein binding $0.22 \mu \mathrm{m}$ Millex-GV filters (Millipore Corp., Bedford, MA), alternatively through molecular weight cut-off (MWCO) filtering at $30 \mathrm{kDa}$ (LIDA Manufacturing Corp., Kenosha, WI).

\subsection{Antibodies and receptor blocking}

The specific monoclonal antibodies M 0741 (mouse anti-human CD11b, clone 2LPM19c), the corresponding X 0931 (mouse $\mathrm{IgG}_{1}$ negative control), M 7084 (anti-human CD62L, clone FMC46), R 7058 (R-phycoerythrin (RPE)-conjugated mouse anti-human CD41, clone 5B12), X0928 (RPE-conjugated mouse $\mathrm{IgG}_{1}$ negative control) and polyclonal antibodies A 424 (anti-IgG, specific for $\gamma$-Chains) and A 0001 (anti-Albumin) were from Dakopatts (Glostrup, Denmark). Monoclonal F(ab') $)_{2}$ :s RDI-023-301 (mouse anti-human CD 32, clone IV.3), RDI-028-201X (mouse anti-human CD 16, clone 3G8), mouse $\operatorname{IgG}_{2}$ isotype control antibody RDI-MSIGG2A-X (clone G155-178) and polyclonal RDI-CD62Ppabr (rabbit antihuman CD62P) were from Research Diagnostics, Inc. (Flanders, NJ). Mouse anti-human CD162 (clone 3E2.25.5/PL1 and clone 5D8.8.12.10/PL2) and corresponding MCA928 mouse $\operatorname{IgG}_{1}$ negative control (clone W3/25) were from Serotec (Oxford, U.K.). Monoclonal fluorescein isothiocyanate (FITC)conjugated mouse IgG1, $\kappa$ immunoglobulin isotype standard number 550616 (clone MOPC-31C) and antihuman CD62P number 31794X (clone AK-4) antibodies were purchased from BD Biosciences, PharMingen (San Diego, CA). The secondary antibody A-11001 Alexa Fluor ${ }^{\circledR} 488$ goat anti-mouse IgG 
was from Molecular Probes, Inc. (Eugene, OR), P1-peptide (H-KYGWTVFQKKRLDGSV-OH) from Research Genetics (Huntsville, AL), and recombinant human P-selectin (CD62P) from R\&D Systems (Minneapolis, MN).

Monoclonal antibodies containing azide were first submitted to a 3-hour small-volume dialysis in 10 kDa MWCO Slide-A-Lyzer ${ }^{\circledR}$ cassettes (Pierce Chemical Company, Rockford, IL) at $4^{\circ} \mathrm{C}$ against PBS with at least three buffer changes before presentation to viable cells. During the receptor blocking studies, neutrophils were typically pre-incubated on ice $\left(5 \mu \mathrm{g}\right.$ antibody per $10^{6}$ cells) and platelets at room temperature $\left(5 \mu \mathrm{g}\right.$ antibody per $10^{8}$ cells).

\subsection{Model surfaces}

Aminated (amino-propyl-trimethoxysilane, APTMS) silicon particles with an average diameter of $20 \mu \mathrm{m}$ (non-phagocytosable as determined by morphological evaluation) were purchased from Gerlinde Kisker GbR (Steinfurt, Germany). Major findings obtained by use of these particles were verified in control experiments with particles from other manufacturers (for instance Polybead ${ }^{\circledR}$ polystyrene $20 \mu \mathrm{m}$ microspheres, Polysciences, Inc., Warrington, PA).

Glass test tubes (40 x 8 mm, Assistent KHG, Sondheim-Rhön, Germany) were cleaned for 5 min at $80^{\circ} \mathrm{C}$ in 5:1:1 parts of distilled water, hydrogen peroxide $(30 \% \mathrm{v} / \mathrm{v})$ and $\mathrm{NH}_{4} \mathrm{OH}(25 \% \mathrm{v} / \mathrm{v})$. The tubes were then rinsed ten times in distilled water and hydrophilized (water/surface static contact angle, $\theta_{\mathrm{w}},<10^{\circ}$, Ramé-Hart NRL Model 100 goniometer) by another $5 \mathrm{~min}$ at $80^{\circ} \mathrm{C}$ in $6: 1: 1$ parts of distilled water, hydrogen peroxide and hydrochloric acid $(37 \% \mathrm{v} / \mathrm{v})$. Hydrophilic tubes were washed in distilled water, then in technically pure ethanol and finally in xylene (Merck, Darmstadt, Germany). The tubes were hydrophobized $\left(\theta_{\mathrm{w}}>90^{\circ}\right)$ by methylation for $5 \mathrm{~min}$ at room temperature in $1 \%(\mathrm{v} / \mathrm{v})$ dichlorodimethylsilane $\left(\mathrm{Cl}_{2}\left(\mathrm{CH}_{3}\right)_{2} \mathrm{Si}\right)$ in xylene. Traces of silane were removed by excessive sequential rinsing in ethanol, then xylene and finally ethanol. 


\subsection{Protein coatings and null-ellipsometry}

APTMS-coated silicon particles were pelleted by 5 min centrifugation at $300 \mathrm{x} g$, washed in PBS and incubated for $30 \mathrm{~min}$ at room temperature in Tris buffer ( $\mathrm{pH} 9)$ containing $6 \%$ glutaraldehyde (Merck, Darmstadt, Germany). After three washings in PBS for $5 \mathrm{~min}$ at $300 \mathrm{x}$, the particles were incubated for 30 min at room temperature in $1 \mathrm{mg} / \mathrm{mL}$ of normal human $\mathrm{IgG}$ or albumin (Pharmacia \& UpJohn, Stockholm, Sweden), and again washed twice in PBS for 5 min at $300 \mathrm{x} g$. The procedure yields a covalently bound protein monolayer with an approximate thickness of $2.7 \mathrm{~nm} \mathrm{IgG} \mathrm{and} 1.2 \mathrm{~nm}$ albumin on similarly treated (amino-propyl-triethoxysilane, Merck) silicon wafers (Okmetic LMTD, Esbo, Finland) as verified by null

ellipsometry (Rudolf Research AutoEl III, NJ) combined with antibody techniques (polyclonals from Dakopatts, above) [21]. Washed IgG- and albumin-coated APTMS-particles $\left(1 \times 10^{6} / \mathrm{mL}\right)$ were endotoxinnegative in the Limulus Amebocyte Lysate end-point COATEST ${ }^{\circledR}$ (Charles River Endosafe, Carleston, SC). In fluorescence microscopy studies (below), 4\% paraformaldehyde in PBS was used instead of glutaraldehyde.

Hydrophobic tubes adsorbed spontaneously (and non-covalently) one monolayer of IgG (approximately $3.4 \mathrm{~nm}$ as measured by ellipsometry on similarly treated silicon wafers [21]) or albumin (approximately $1.8 \mathrm{~nm}$ ) after $30 \mathrm{~min}$ of incubation in $1 \mathrm{mg} / \mathrm{mL}$ protein in PBS at room temperature. Nonadsorbed proteins were removed with PBS. IgG or albumin was also adsorbed through the same procedure inside hydrophilic glass test tubes. A ten-fold increase of the coating protein concentration did not increase the adsorbed layer thickness on any of the surfaces. The presence of $\mathrm{IgG}$ and albumin at surfaces was verified through the incubation of flat hydrophobic surfaces in respective specific polyclonal antibody solution (A 424 and A 0001 at 1/50 dilutions in PBS), followed by ellipsometric determination of the deposited mass. 


\subsection{Chemiluminescence}

The neutrophil respiratory burst in response to plasma protein coated hydrophobic or hydrophilic glass tubes was studied by luminol-amplified chemiluminescence (CL) in a calibrated six-channel Biolumat (LB 9505 C, Berthold Co., Wildbaden, Germany), essentially as previously described [22, 23]. Platelets were re-calcified and pre-incubated at $37^{\circ} \mathrm{C} 5 \mathrm{~min}$ before addition of $4 \mathrm{U} / \mathrm{mL}$ horseradish peroxidase (Boehringer Mannheim GmbH, Mannheim, Germany), $50 \mu \mathrm{M}$ luminol (5-amino-2,3-dihydro-1,4phtalazinedione) and neutrophils, whereupon both intra- and extracellulary produced ROS was monitored for half an hour. The intracellular generation of ROS was registered in experiments with exchange of extra peroxidase for superoxide dismutase and catalase $(200 \mathrm{U} / \mathrm{mL}$ and 2,000 U/mL, respectively, Boehringer Mannheim) that removes extracellular superoxide anion and hydrogen peroxide.

\subsection{Lumi-aggegometry and particulate stimuli}

ROS-generation, ATP-secretion and cell-cell/cell-material aggregation in neutrophil and/or platelet suspensions, stimulated with protein coated particles, were measured under stirring conditions using a calibrated two-sample Lumi-Aggregometer model 560 (Chrono-Log Corp., Havertown, PA; manufacturer of all products identified by \# and number, below). The instrument allows a simultaneous recording of luminescence and aggregation in real-time through double optical and double luminescence channels.

The ATP release was measured using the Chrono-lume ${ }^{\circledR}$ reagent \#395 (176 U/mL luciferase and $1.6 \mu \mathrm{g} / \mathrm{mL}$ luciferin), and the concentration of extracellular ATP was quantified by adding a known amount of ATP (Chrono-Par \#387) at the end of each measurement. Neutrophils and platelets were allowed to equilibrate at $37^{\circ} \mathrm{C}$ for $5 \mathrm{~min}$ in polystyrene cuvettes (\#367) under stirring. The stirring was achieved by disposable siliconized stir bars (\#370), and the speed was set to $700 \mathrm{rpm}$ to permit cell adhesion to particles, yet providing full aggregation responses by common agonists (tested by others [24]). The cells were then stimulated with $1 \times 10^{5} / \mathrm{mL}$ protein-coated particles and measurements were performed for 15 min. Neutral density filters were used when samples showed a high luminescence. Aggregation data (optical channels) were recorded by measuring the maximum amplitudes on printouts. The results regarding 
ATP-release and CL were collected by export of the luminescence data to KaleidaGraph 3.5 software (Synergy Software, Reading, PA) for calibration, normalization and calculations (integral and maximal values). The CL derived from the APTMS-particles per se was negligible.

\subsection{F-actin and platelet-neutrophil adhesion}

To further evaluate the extent of cellular activation during interaction with particles, adhesion, morphology and distribution of filamentous actin (F-actin) were studied. The experimental conditions were similar to those used in the lumi-aggregometry. After $10 \mathrm{~min}$, the various samples were fixed with $4 \%$ paraformaldehyde in PBS and kept for 30 min on ice. The cells were then washed twice by centrifugation for $2 \mathrm{~min}$ at $9000 \mathrm{x}$ g in PBS, permeabilized and F-actin stained through $30 \mathrm{~min}$ of incubation in 100 $\mu \mathrm{g} / \mathrm{mL}$ lysophosphatidylcholine and $0.6 \mu \mathrm{g} / \mathrm{mL}$ BODIPY $^{\circledR}$ FL phallacidin or $10 \mathrm{U} / \mathrm{mL}$ rhodamine phalloidin (Molecular Probes) in PBS at room temperature. The stained cell samples were washed twice (2 min at $9000 \mathrm{x} g$ in PBS), resuspended in PBS and mounted on slides. The cells were treated similarly when stained for surface receptors (P-selectin, CD41 or PSGL-1) by incubation in $5 \mu \mathrm{g} / \mathrm{mL}$ of primary or secondary FITC-, RPE- or Alexa Fluor ${ }^{\circledR}$-conjugated antibodies (above).

The slides were studied in light and fluorescence microscopy modes with a Zeiss Axioscope (Carl Zeiss, Oberkochen, Germany). Digital images were generated with a Carl Zeiss ZVS-47E digital camera at default settings of the Easy Image Measurement 2000 software (version 2.3, Bergström Instrument AB, Solna, Sweden) and subsequent cropping of the pictures performed with Canvas 5.0 software (Deneba Systems, Inc., Miami, FL).

Quantification of neutrophil adhesion to hydrophobic surfaces was also performed in a control experiment by labeling of neutrophils with $2^{\prime}$, 7'-bis-(carboxy-ethyl)-5(6)-carboxyfluorescein pentaacetoxymethyl ester (Calbiochem, La Jolla, CA, USA), as previously described [22].

\subsection{Statistics}

The data are presented as arithmetic averages \pm SEM and significance in differences were tested with the two-tailed paired Student's $t$-test (Microsoft Excel 1997). Significance levels of $*=\mathrm{p}<0.05 ; * *=$ 
$\mathrm{p}<0.01 ; * * *=\mathrm{p}<0.001$; and NS $=$ not significant, were used and data not indicated by any of the four levels in figures are the $t$-test controls. The number of blood donors is indicated by $n$ (separate experiments for each donor). 


\section{RESULTS}

\subsection{Platelets amplify neutrophil ROS-production on IgG-coated surfaces}

Platelets markedly increased the neutrophil CL-response at IgG-coated hydrophobic surfaces compared to non-coated, an effect that was optimized at a physiological neutrophil/platelet ratio (1/50; Fig. 1A). The platelet-derived CL was then negligible, and the neutrophil response displayed a biphasic shape in the presence of the platelets (Fig. 1B), with a predominantly extracellular ROS release during the first phase and intracellular ROS-production contributing to the second phase (Fig. 1C). The platelets were able to amplify the neutrophil response also on IgG-coated hydrophilic surfaces, although the effect was then less potent and the response monophasic (not shown). In contrast to IgG-coated hydrophobic surfaces, the platelets displayed no potentiation effect on albumin- (Fig. 1B), IgM- (not shown) or non-coated (Fig. 1B) surfaces, clearly indicating a role for the $\mathrm{F}_{\mathrm{cr}}$-receptor. The removal of non-adherent platelets from IgGcoated hydrophobic surfaces prior to the addition of neutrophils did not inhibit the adhered platelet amplification effect. Stimulation with thrombin $(0.5 \mathrm{U} / \mathrm{mL})$ before or during surface interaction showed no significant effect on the CL. The amplification of the neutrophil ROS-generation on IgG-coated surfaces was observed also when washed platelets were replaced with platelet rich plasma (not shown). By studying the adhesion of BCECF- and non-labeled neutrophils, we observed that the presence of platelets on IgGcoated surfaces did not further increase the neutrophil adhesion. The CL-amplification was not totally due to viable platelets since a minor part of the response remained when the neutrophils were co-incubated with

paraformaldehyde-fixed platelets during surface exposure, suggesting that the neutrophil-platelet interaction required contact between surface receptors.

\subsection{The role of integrins and selectins in platelet-neutrophil interaction}

The blocking of neutrophil and platelet $\mathrm{F}_{\mathrm{c \gamma}}$-receptors $\mathrm{CD} 16$ and $\mathrm{CD} 32$, respectively, with monoclonal $\mathrm{F}\left(\mathrm{ab}^{\prime}\right)_{2}$ fragments prior to interaction with IgG-coated surfaces reduced the CL-response by 
approximately one third (Table 1). Thus, in addition to the activation of $\mathrm{F}_{\mathrm{c} \gamma}$-receptors other systems are involved in the regulation of the respiratory burst on IgG-coated surfaces. Blocking of the neutrophil integrin CR3 with the P1 peptide (Table 1) or with monoclonal antibodies showed no inhibitory effects. Similarly, blocking of the platelet integrin GpIIb/IIIa with echistatin or the RGDS-peptide did not affect the platelet-induced CL response in neutrophils (Table 1). In other studies, the interaction between CR3 and $\mathrm{F}_{\mathrm{c} \gamma}$-receptors was counteracted by drugs that disrupt the actin dynamics [25], also on IgG-coated artificial surfaces $[22,26]$. However, we observed that both the actin polymerization inhibitor cytochalasin B and the actin polymerization stabilizer jasplakinolide transiently stimulated the platelet-mediated ROS-production in neutrophils (Fig. 2). This contradicts the previously reported rapid inhibition of integrin dependent ROSgeneration on IgG- and complement-opsonized surfaces [22, 26].

Next, the role of a selectin-dependent interaction between platelets and neutrophils for the regulation of oxidase activity was investigated. We found that dextran sulfate almost completely inhibited the CL-response in a neutrophil/platelet suspension which interacted with IgG-coated hydrophobic glass (Table 1). We also found that the platelet-mediated enhancement of the IgG-triggered neutrophil respiratory burst was inhibited by $23 \%$ by anti-P-selectin and $21 \%$ by anti-PSGL-1 (Table 1 ). However, recombinant P-selectin could not mimic the effects of platelets on the neutrophil oxidase activity at IgG-coated surfaces (not shown). Our experiments argue against a role for neutrophil L-selectin since blocking of L-selectin with anti-L-selectin could not antagonize the stimulatory effects on neutrophil oxidase activity at IgGcoated surfaces (Table 1).

\subsection{Stirring conditions influence the ROS-production}

The presence of platelets caused an approximately three-fold enhancement of the neutrophil respiratory burst during interaction with IgG-coated particles under stirring conditions (Fig. 3A). The response was monophasic (peak after approximately $5 \mathrm{~min}$ ), mainly extracellular and required viable platelets (Fig. 3B). The NADPH-oxidase inhibitor diphenyleneiodonium (DPI, $5 \mu \mathrm{M})$ blocked the ROS- 
generation (not shown). The neutrophil CL-response was approaching basal levels on non-coated particles when platelets were introduced (Fig. 3A). In contrast to IgG, albumin did not amplify the platelet-related neutrophil ROS-production (Fig. 3A). The albumin-coated particles gave rise to a minor additive effect on the neutrophil respiratory burst, although the albumin-triggered response in a mixed neutrophil/platelet suspension did not differ from that of platelets alone (Fig. 3A).

Also the platelet alone system generated ROS upon stimulation with particles (Fig. 3A). However, the response did not depend on the protein coating and was probably induced by shear and/or collision effects. When the platelets were stimulated with IgG-particles for up to $5 \mathrm{~min}$ and the particles then allowed to sediment, the remaining particle-free platelet fraction triggered a potent neutrophil CL-response (Fig. 3C). This phenomenon was lowered by approximately $85 \%$ after filtration through $0.22 \mu \mathrm{m}$ (Fig. 3D) or 30 kDa MWCO filters, suggesting an important role for membrane-bound platelet factors. In accordance with this, paraformaldehyde-fixation of the "IgG-stimulated platelet fraction" followed by triplicate washings did not abolish the stimulatory effect of platelets.

\subsection{The role of PSGL-1 is pronounced under stirring conditions}

Similar to the non-shearing conditions on hydrophobic glass, blocking of neutrophil and platelet $\mathrm{F}_{\mathrm{cr}}$-receptors did not result in a total quenching of the platelet-mediated neutrophil CL-response during contact with IgG-coated particles. This suggests the involvement of other receptors. The potentiating effect of platelets on the neutrophil oxidase activity resembles the previously reported effect of IgG in normal human serum $[22,23]$. While the serum triggered neutrophil CL-response was disrupted by drugs that interfere with the actin cytoskeleton (cytochalasin B and jasplakinolide [22, 26]), the platelet-induced neutrophil oxidase activity in the presence of IgG-coated particles was unaffected, arguing against a tentative interaction between neutrophil CR3 and platelet GpIIb/IIIa as the main effector mechanism during the amplification process.

Blocking of neutrophil PSGL-1 (with the PL1 antibody) decreased the IgG-platelet mediated CLresponse by approximately 43\% (Fig. 4A). Antibodies against neutrophil L-selectin (FMC46) or corresponding control antibodies displayed no effects (Fig. 4A). Neither anti-PSGL-1, nor anti-L-selectin 
induced detectable CL-responses by themselves. The data suggest a pronounced interaction between neutrophil PSGL-1 and platelet P-selectin on IgG-coated particles. In support to this hypothesis, the intracellular events that are triggered by neutrophil PSGL-1 are reported to be accompanied by an intracellular tyrosine phosphorylation [27]. Accordingly, the present IgG-triggered CL in the platelet/neutrophil cell suspension was inhibited by $35 \%$ by the tyrosine kinase inhibitor genistein $(10 \mu \mathrm{M})$, and the genistein inhibitory effect was even more potent (57\% inhibition) when the neutrophils were instead stimulated with platelet fractions that were pre-exposed to IgG-coated particles (not shown).

\subsection{Particle triggered aggregation and ATP secretion}

Platelets alone or platelet-neutrophil suspensions that interacted with $\operatorname{IgG}$ demonstrated a moderate aggregation within 15 min after stimulation (Fig. 5A) and blocking of platelet $\mathrm{F}_{\mathrm{cr}}$-receptors with monoclonal antibody fragments inhibited this (not shown). The aggregation required viable platelets and equaled about $25-30 \%$ of the response induced by collagen (a potent platelet agonist). The IgG-triggered neutrophil aggregation was very modest and not significantly different from that on albumin (Fig. 5A). However, the neutrophils were still able to aggregate in response to IgG-particles when mixed with paraformaldehyde-fixed platelets (not shown). Albumin-coatings induced low aggregation of both neutrophils and platelets (Fig. 5A). The IgG-triggered platelet aggregation, and this was regardless of the presence or absence of neutrophils, depended on ROS in the extracellular compartment (Fig 5B). Catalase but not superoxide dismutase antagonized platelet aggregation, suggesting that hydrogen peroxide was essential for the platelet aggregation after stimulation with immobilized IgG. However, the aggregation of neutrophils did not depend on the release of extracellular ROS (Fig. 5B). The actin drugs cytochalasin B, jasplakinolide and latrunculin B and antibodies against neutrophil PSGL-1 and L-selectin (Fig. 4B) did apparently not affect the IgG-triggered aggregation.

The platelets released only small amounts of ATP upon contact with the particles, and no significant differences were found between the various protein coatings (Fig. 5C). Thus, stimulation with particles did not induce a substantial dense granule secretion. 


\subsection{Platelets support neutrophil adhesion}

A morphological examination of paraformaldehyde-fixed samples verified the aggregation responses; i.e. predominantly solitary cells and particles were observed on albumin-coated samples, and aggregates of neutrophils, platelets and particles on IgG-coated samples (Fig. 6). The platelets appeared activated, fragmented, and acted most often as linkers between the IgG-coated particles and neutrophils (Fig. 6). However, not all cells were associated to particles. Numerous soluble aggregates of neutrophils, platelets and possibly platelet microparticles were documented after stimulation with IgG-coated particles (Fig. 7). On the other hand, only few small-volume aggregates were found after stimulation with albumincoated particles (not shown). When the neutrophils were incubated in platelet solutions that were preexposed to IgG-coated particles, large numbers of neutrophil-platelet aggregates (with morphology similar to Fig. 7) appeared, as well as solitary neutrophils with platelets associated to their surfaces (Fig. 8). Solitary neutrophils observed after stimulation with albumin-coated particles were not observed in the $\operatorname{IgG}$ system. Platelets and platelet fragments were P-selectin positive already after 1 min of interaction with IgGparticles (using FITC-conjugated monoclonal antibodies and fluorescence microscopy). Also, most neutrophils (and many platelets) were PSGL-1 positive after 3 min of interaction with the IgG-coated particles in mixed cell suspensions (cells stained with PL2 as primary and A-11001 as secondary antibody, compared to corresponding control). 


\section{DISCUSSION}

This study demonstrate that platelets play an important role for the regulation of the neutrophil respiratory burst at artificial surfaces during blood contact. The platelet-neutrophil interactions depend then on the type of protein coating and shear conditions. The blood cell interaction with implanted devices is preceded by a rapid (within seconds) adsorption of plasma proteins such as albumin and IgG. Neutrophils that interacted with IgG-coated hydrophobic glass displayed in our study a substantial ROS-production, and immobilized albumin suppressed the neutrophil respiratory burst. We demonstrate here that platelets markedly amplify the neutrophil ROS-production during interactions with non-phagocytosable IgGopsonized surfaces, under shear and non-shear conditions.

$\operatorname{IgG}$ is identified as one of the early deposited proteins at artificial surfaces upon contact with body fluids [28]. Tang and Eaton showed that IgG-deficient mice apparently respond with a normal inflammatory reaction after implantation [29], but in another study a very potent in vivo inflammatory reaction was triggered by surface-bound $\operatorname{IgG}[30]$. We have previously demonstrated that platelets amplify the IgG-triggered neutrophil respiratory burst in response to phagocytosable [17] and non-phagocytosable preys [31] in non-stirred systems. However, the mediators of these effects were not identified. We observed in the present and in the previous study [31] that adhered platelets were fragmented at IgG-coated surfaces in platelet-neutrophil suspensions, similar to the observation by Broberg and Nygren [32] when the platelets adhered in the absence of shear.

Platelets are known to bind more rapidly than neutrophils to artificial surfaces $[4,33]$, and a tentative scenario where platelets adhere, become activated by pre-adsorbed proteins, and then regulate the subsequent behavior of other inflammatory cells including neutrophils is likely. Such regulatory mechanisms could involve secretion of stored soluble platelet mediators (e.g. by affecting neutrophil $\mathrm{F}_{\mathrm{c} \gamma^{-}}$ receptors [34]), although the dense granule secretion (measured as ATP-release) was low in the present study and the role of soluble mediators was probably of minor importance. Our observations suggest that platelets and platelet-derived fragments not only act as bystanders during the amplification of the neutrophil 
respiratory burst, but are a prerequisite for an effective recruitment of neutrophils to IgG-coated surfaces: $i$ ) microscopic examination revealed that the major part of adhered neutrophils bound to spread platelets or platelet fragments on the IgG-coated particles ii) a substantial neutrophil ROS-production was obtained when the neutrophils were stimulated with viable or fixed platelets that were pre-exposed to IgG-coated particles iii) the stimulatory effect by pre-stimulated platelets was inhibited by filtration (through $0.22 \mu \mathrm{m}$ or $30 \mathrm{kDa}$ MWCO). Consequently, the data suggest that platelets activate the neutrophil ROS-production through membrane-associated factors.

The neutrophil oxidase activity was to a large extent triggered by other neutrophil receptors than $\mathrm{F}_{\mathrm{cy}}$. Is there also a neutrophil CR3 and platelet integrin GpIIb/IIIa interaction in our study? Others and we have previously demonstrated that integrin-dependent ROS-production, e.g. by neutrophils that interact with surface-deposited complement activated by $\operatorname{IgG}$, depend on a dynamic actin cytoskeleton for the coupling of CR3 to the NADPH-oxidase $[22,25,26]$. We found in the present study that actin filament inhibitors that block de novo expression of integrins [35] had no inhibitory effect on the oxidative burst of neutrophils and platelets that interacted with the IgG-coated surfaces. Furthermore: $i$ ) blocking of neutrophil integrin CR3 or platelet integrin GpIIb/IIIa showed no effect ii) neutrophil CL-amplification by platelets did not correspond to complement-dependent CL-kinetics iii) complement activation that was triggered by immobilized IgG required $>1 \%$ serum for a detectable surface-deposition of the CR3-ligand complement factor 3 , and since we used washed platelets no complement was available. Such data argue for integrin-independent mechanisms.

P-selectin promotes the accumulation and emigration of neutrophils during inflammation and thrombosis [16], and its ligand PSGL-1 is probably very important for the early neutrophil activation, including rolling along endothelial P-selectin [36,37]. The results in this study suggest a major contribution of platelet derived components to trigger the P-selectin/PSGL-1 interaction. Platelets may release at least two separate types of membrane vesicles, microvesicles and exosomes (referred to as microparticles) in response to agonistic stimulation or during high shear conditions [38]. Microparticles are P-selectin positive and may aggregate neutrophils, presumably via PSGL-1 $[39,40]$. Indeed, artificial surfaces $[4,41$, 
42] and surface-immobilized $\operatorname{IgG}[32]$ are both capable to induce platelet fragmentation and microparticle formation. Adsorbed P-selectin-positive microparticles $(>0.1 \mu \mathrm{m})$ in the proximity of platelet pseudopodia was recently documented on synthetic surfaces [43]. Platelet microparticles mediate PSGL-1 (but not Lselectin) dependent neutrophil-neutrophil aggregation also under flow [44], thus supporting the present observation that platelets or platelet derived microparticles act as linkers between biomaterial/neutrophil and neutrophil/neutrophil aggregates.

The specific anti-PSGL-1 antibody PL1 gave rise to a potent inhibition of the IgG-triggered platelet-neutrophil interaction. PL1 blocks the PSGL-1 interaction with P-selectin by binding over the PSGL-1 tyrosine sulfation sites [45]. Stimulation of PSGL-1 induces tyrosine phosphorylation [27] and, consequently, the present interaction was inhibited by the tyrosine kinase inhibitor genistein. Furthermore, cytochalasin B does not affect the tyrosine phosphorylation that accompanies neutrophil PSGL-1 occupancy [46] and, accordingly, we could not interrupt the platelet amplification of the IgG-triggered respiratory burst by addition of any of the actin drugs.

Neutrophil PSGL-1 is a highly extended microvilli molecule that provides interaction with Pselectin, especially under flow [45]. Consequently, the CL-response effect of anti-PSGL-1 was especially potent under stirring conditions. Furthermore, Tsuji et al. demonstrated that thrombin-activated platelets enhanced the extracellular release of superoxide anion from neutrophils via P-selectin interaction with sialyl Lewis X [47]. They also noticed, in accordance with Wong et al. and the present study, that soluble recombinant P-selectin rather inhibited than potentiated the effects on the neutrophil respiratory burst [47, 48]. This is probably due to that isolated platelet P-selectin is dimeric, both in $\alpha$-granules of resting cells and on activated platelet surfaces [49]. Dimeric P-selectin has a higher binding affinity to PSGL-1 than monomeric P-selectin, and dimerization of PSGL-1 is essential for a functional interaction with P-selectin [50]. Thus, as expected, the recombinant monomeric P-selectin did not mimic the "platelet effect" in the present study. Frenette and co-workers demonstrated the presence of biologically active PSGL-1 on platelet membranes, although at lower densities than on neutrophils [51]. In our study, the presence of PSGL-1 on neutrophil and platelet membranes was confirmed by fluorescence microscopy 
Since P-selectin is rapidly (minutes) released from activated platelets during activation [52, 53], and activated platelets quickly form aggregates with leukocytes in vivo, it has been suggested that the formation of platelet-leukocyte aggregates is a better marker of platelet activation than P-selectin expression [54]. Large portion of the neutrophil and platelet populations is actually circulating aggregates with enhanced inflammatory capabilities. Such aggregates may be dissolved by anti-P-selectin [55]. Singlet oxygen, presumably neutrophil derived, may also inhibit and reverse platelet aggregation [56-58] and inhibit platelet P-selectin expression [58]. In our experiments, we found P-selectin positive platelets and platelet fragments already after a very brief $(1 \mathrm{~min})$ interaction with IgG-coated particles. A similar observation was made by Broberg and Nygren [32]. We observed, in accordance with Michelsson and coworkers [54], that the time scale was important for the detection of P-selectin. For instance, when prestimulated viable platelet fractions were stored for longer time (>10 min), the stimulatory effect on the neutrophil respiratory burst became markedly reduced.

Our results suggest a major role for P-selectin - PSGL-1 interactions. The PL1 antibody trigger tyrosine phosphorylation and platelet-neutrophil aggregation $[27,46]$, but we observed no effect on the neutrophil aggregation or CL-response when PL1 was instead given as a stimuli. Also, PSGL-1 triggered tyrosine phosphorylation is suggested to enhance the neutrophil-platelet adhesion via CR3 [59], a phenomenon not supported by our data.

The blood stream provides a low to high shear environment. However, neutrophil functions are often performed at low shear in the tissue after extravasation from blood vessels. Despite what shear that may be relevant in the case of biomaterials, we demonstrate that platelet-neutrophil activities differ under stirred and non-stirred conditions, respectively. The CL-response of non-stirred neutrophils contained a secondary intracellular part, whereas the response under stirred conditions was explicitly extracellular. One explanation to this may be that the second phase of the CL-response in the non-stirred system was due to neutrophil phagocytosis of platelets or their fragments. The ability of neutrophils to phagocytose platelets has been demonstrated [60]. In support to this, the second peak in the non-stirred system resembled the response observed in a previous study when platelet-neutrophil suspensions were stimulated with phagocytosable IgG-opsonized yeast [17]. 
Another interesting difference between the non-stirred and stirred experimental set-ups was that platelets contributed directly to the respiratory burst during the latter condition, and this ROS-production was essential for the aggregation to occur. Actually, platelets have been shown to produce ROS under shear in response to stimuli including collagen [61], iron [62] and lipopolysaccharide [63]. The enzyme-system that generates ROS in platelets is not characterized, although the involvement of an NADH/NADPHoxidase system has been suggested [64]. Also, neutrophil release products could impair the platelet aggregation capability $[65,66]$. In contrast, micromolar concentrations of hydrogen peroxide enhance platelet aggregation induced by other stimuli $[67,68]$, and myeloperoxidase and hydrogen peroxide are suggested to activate platelet secretion [69]. These effects can be reversed by catalase. However, the platelet aggregation that was observed in the present study occurred without the presence of peroxidase and an accompanying secretion.

In conclusion, activated platelets on IgG-coated surfaces bind selectively to and stimulate neutrophils. The intercellular signaling is mediated by membrane-bound platelet-derived P-selectin and

neutrophil PSGL-1, and aparently independent of integrins. This finding may be important for the understanding of the inflammatory response at biomaterial interfaces, biomaterial-related infections and for the handling of immune complexes in a vast number of inflammatory disorders.

\section{ACKNOWLEDGEMENTS}

We thank Agneta Askendal and Kristina Orselius for support. This work was funded by the Biocompatible Materials Program, the Swedish Biomaterials Consortium (Swedish National Foundation for Strategic Research), and by the Swedish Medical Research Council (grant number 71X-12668). 


\section{REFERENCES}

$1 \quad$ Tang L, Eaton JW. Inflammatory responses to biomaterials. Am J Clin Pathol 1995;103:466-71.

2 Vroman L, Adams AL. Identification of rapid changes at plasma-solid interfaces. J Biomed Mater Res 1969;3:43-67.

3 Andrade JD, Hlady V. Plasma protein adsorption: the big twelve. Ann NY Acad Sci $1987 ; 516: 158-72$.

Nygren H, Braide M, Karlsson C. Protein-platelet and platelet-leukocyte interaction at materials in contact with human blood. J Vac Sci Technol A 1995;13:2613-2618.

5 Leto TL. The respiratory burst oxidase. In: Gallin, JI and Snyderman, R, eds. Inflammation: Basic principles and clinical correlates. Philadelphia: Lippincott Williams \& Wilkins, 1999. p. 769-786.

$6 \quad$ Babior BM. NADPH oxidase: an update. Blood 1999;93:1464-76.

7 Elsbach P, Weiss J, Levy O. Oxygen-independent antimicrobial systems of phagocytes. In: Gallin, JI and Snyderman, R, eds. Inflammation: Basic principles and clinical correlates. Philadelphia: Lippincott Williams \& Wilkins, 1999. p. 801-817.

8 Kaplan SS, Basford RE, Jeong MH, Simmons RL. Biomaterial-neutrophil interactions: dysregulation of oxidative functions of fresh neutrophils induced by prior neutrophil-biomaterial interaction. J Biomed Mater Res 1996;30:67-75.

9 Marcus AJ. Platelets: Their role in Hemostasis, Thrombosis, and Inflammation. In: Gallin, JI and Snyderman, R, eds. Inflammation: Basic principles and clinical correlates. Philadelphia: Lippincott Williams \& Wilkins, 1999. p. 77-95.

Diacovo TG, Roth SJ, Buccola JM, Bainton DF, Springer TA. Neutrophil rolling, arrest, and transmigration across activated, surface-adherent platelets via sequential action of P-selectin and the beta 2-integrin CD11b/CD18. Blood 1996;88:146-57.

Brown KK, Henson PM, Maclouf J, Moyle M, Ely JA, Worthen GS. Neutrophil-platelet adhesion: relative roles of platelet P-selectin and neutrophil beta2 (DC18) integrins. Am J Resp Cell Mol Biol 1998;18:100-10. 

glycoprotein ligand from human neutrophils displays sialylated, fucosylated, O-linked poly-Nacetyllactosamine. J Biol Chem 1994;269:23318-27.

13 Picker L, Warnock R, Burns A, Doerschuk C, Berg E, Butcher E. The neutrophil selectin LECAM-1 presents carbohydrate ligands to the vascular selectins ELAM-1 and GMP-140. Cell 1991;66:921-933.

14 Ruf A, Patscheke H. Platelet-induced neutrophil activation: platelet-expressed fibrinogen induces the oxidative burst in neutrophils by an interaction with CD11C/CD18. Br J Haematol 1995;90:791-6. Simon DI, Chen Z, Xu H, Li CQ, Dong Jf, McIntire LV, Ballantyne CM, Zhang L, Furman MI, Berndt MC, Lopez JA. Platelet glycoprotein ibalpha is a counterreceptor for the leukocyte integrin Mac-1 (CD11b/CD18). J Exp Med 2000;192:193-204. neutrophil locomotion: evidence for a role of P-selectin. Scand J Clin Lab Invest 1999;59:439-49. mediated phagocytosis and respiratory burst in neutrophils: the role of purinergic modulation and actin polymerization. J Leukocyte Biol 1996;60:58-68.

Böyum A. Isolation of mononuclear cells and granulocytes from human blood. Isolation of monuclear cells by one centrifugation, and of granulocytes by combining centrifugation and sedimentation at 1 g. Scand J Clin Lab Invest Suppl 1968;97:77-89.

Ferrante A, Thong YH. Optimal conditions for simultaneous purification of mononuclear and polymorphonuclear leucocytes from human blood by the Hypaque-Ficoll method. J Immunol Methods 1980;36:109-17.

Bengtsson T, Grenegård M. Platelets amplify chemotactic peptide-induced changes in F-actin and calcium in human neutrophils. European J Cell Biol 1994;63:345-9. surfaces in vitro. Biomaterials 2001;23:981-991. 

hydrophobic surfaces enhances the release of oxygen radicals from neutrophils through an actindependent mechanism. J Biomed Mater Res 2000;51:742-51. immunoglobulin M-coated surfaces. J Biomed Mater Res 2001;57:550-8. platelet aggregation in the absence and presence of extracellular ATP. Thromb Res 2000;97:15-27. Zhou MJ, Brown EJ. CR3 (Mac-1, alpha M beta 2, CD11b/CD18) and Fc gamma RIII cooperate in generation of a neutrophil respiratory burst: requirement for Fc gamma RIII and tyrosine phosphorylation. J Cell Biol 1994;125:1407-16.

Liu L, Elwing H, Karlsson A, Nimeri G, Dahlgren C. Surface-related triggering of the neutrophil respiratory burst. Characterization of the response induced by $\operatorname{IgG}$ adsorbed to hydrophilic and hydrophobic glass surfaces. Clin Exp Immunol 1997;109:204-10. Evangelista V, Manarini S, Sideri R, Rotondo S, Martelli N, Piccoli A, Totani L, Piccardoni P, Vestweber D, de Gaetano G, Cerletti C. Platelet/polymorphonuclear leukocyte interaction: Pselectin triggers protein-tyrosine phosphorylation-dependent CD11b/CD18 adhesion: role of PSGL-1 as a signaling molecule. Blood 1999;93:876-85.

Tengvall P, Askendal A, Lundström I. Complement activation by 3-mercapto-1,2-propanediol immobilized on gold surfaces. Biomaterials 1996;17:1001-7.

Tang L, Eaton JW. Fibrin(ogen) mediates acute inflammatory responses to biomaterials. J Exp Med 1993;178:2147-56.

Källtorp M, Askendal A, Thomsen P, Tengvall P. Inflammatory cell recruitment, distribution, and chemiluminescence response at IgG precoated- and thiol functionalized gold surfaces. J Biomed Mater Res 1999;47:251-9.

31 Nimeri G, Öhman L, Elwing H, Wetterö J, Bengtsson T. The influence of plasma proteins and platelets on oxygen radical production and F-actin distribution in neutrophils adhering to polymer surfaces. Biomaterials 2002;23:1785-1795. 
Broberg M, Nygren H. Platelet interaction with surface-immobilized IgG induces the secretion of surface bound microparticles and fragmentation of the cells. Colloids Surf B 1998;10:251-262. hydrophobic glass surfaces: effects of heparin and hirudin on von Willebrand factor binding and CD62 exposure on platelets. Colloids Surf B 1998;11:123-30. neutrophilic Fc gamma receptors. J Leukocyte Biol 1998;64:631-5. adhesion as well as rigidity of neutrophils. Biochem Biophys Res Comm 1997;238:910-5. BC, Furie B. Targeted gene disruption demonstrates that P-selectin glycoprotein ligand 1 (PSGL1) is required for P-selectin-mediated but not E-selectin-mediated neutrophil rolling and migration. J Exp Med 1999;190:1769-82. Norman KE, Katopodis AG, Thoma G, Kolbinger F, Hicks AE, Cotter MJ, Pockley AG, Hellewell PG. P-selectin glycoprotein ligand-1 supports rolling on E- and P-selectin in vivo. Blood 2000;96:3585-91.

Heijnen HF, Schiel AE, Fijnheer R, Geuze HJ, Sixma JJ. Activated platelets release two types of membrane vesicles: microvesicles by surface shedding and exosomes derived from exocytosis of multivesicular bodies and alpha-granules. Blood 1999;94:3791-9. Jy W, Mao WW, Horstman L, Tao J, Ahn YS. Platelet microparticles bind, activate and aggregate neutrophils in vitro. Blood Cells, Molecules, and Diseases 1995;21:217-31. Nomura S, Okamae F, Abe M, Hosokawa M, Yamaoka M, Ohtani T, Onishi S, Matsuzaki T, Teraoka A, Ishida T, Fukuhara S. Platelets expressing P-selectin and platelet-derived microparticles in stored platelet concentrates bind to PSGL-1 on filtrated leukocytes. 2000;6:21321.

41 Gemmell CH, Ramirez SM, Yeo EL, Sefton MV. Platelet activation in whole blood by artificial surfaces: identification of platelet-derived microparticles and activated platelet binding to leukocytes as material-induced activation events. J Lab Clin Med 1995;125:276-87. 
Gemmell C. Activation of platelets by in vitro whole blood contact with materials: Increases in microparticle, procoagulant activity and soluble P-selectin blood levels. J Biomaterials Sci, Polymer Ed 2001;12:993-943. microparticles on synthetic surfaces observed by atomic force microscopy and fluorescence microscopy. Biomaterials 1999;20:1521-9.

Forlow SB, McEver RP, Nollert MU. Leukocyte-leukocyte interactions mediated by platelet microparticles under flow. Blood 2000;95:1317-1323. Li F, Erickson HP, James JA, Moore KL, Cummings RD, McEver RP. Visualization of P-selectin glycoprotein ligand-1 as a highly extended molecule and mapping of protein epitopes for monoclonal antibodies. J Biol Chem 1996;271:6342-8.

Hidari KI, Weyrich AS, Zimmerman GA, McEver RP. Engagement of P-selectin glycoprotein ligand-1 enhances tyrosine phosphorylation and activates mitogen-activated protein kinases in human neutrophils. J Biol Chem 1997;272:28750-6.

Tsuji T, Nagata K, Koike J, Todoroki N, Irimura T. Induction of superoxide anion production from monocytes an neutrophils by activated platelets through the P-selectin-sialyl Lewis $\mathrm{X}$ interaction. J Leukocyte Biol 1994;56:583-7.

48 Wong CS, Gamble JR, Skinner MP, Lucas CM, Berndt MC, Vadas MA. Adhesion protein GMP140 inhibits superoxide anion release by human neutrophils. Proc Nat Acad Sci $1991 ; 88: 2397-401$.

49 Barkalow FJ, Barkalow KL, Mayadas TN. Dimerization of P-selectin in platelets and endothelial cells. Blood 2000;96:3070-7.

Snapp KR, Craig R, Herron M, Nelson RD, Stoolman LM, Kansas GS. Dimerization of P-selectin glycoprotein ligand-1 (PSGL-1) required for optimal recognition of P-selectin. J Cell Biol 1998;142:263-70.

Frenette PS, Denis CV, Weiss L, Jurk K, Subbarao S, Kehrel B, Hartwig JH, Vestweber D, Wagner DD. P-Selectin glycoprotein ligand 1 (PSGL-1) is expressed on platelets and can mediate platelet-endothelial interactions in vivo. J Exp Med 2000;191:1413-22. 
In vivo tracking of platelets: circulating degranulated platelets rapidly lose surface P-selectin but continue to circulate and function. Proc Nat Acad Sci 1996;93:11877-82.

Dore M. Platelet-leukocyte interactions. Am Heart J 1998;135:S146-51.

Michelson AD, Barnard MR, Krueger LA, Valeri CR, Furman MI. Circulating monocyte-platelet aggregates are a more sensitive marker of in vivo platelet activation than platelet surface Pselectin: studies in baboons, human coronary intervention, and human acute myocardial infarction. Circulation 2001;104:1533-7.

55 Peters MJ, Dixon G, Kotowicz KT, Hatch DJ, Heyderman RS, Klein NJ. Circulating plateletneutrophil complexes represent a subpopulation of activated neutrophils primed for adhesion, phagocytosis and intracellular killing. Br J Haematol 1999;106:391-9.

56 Stief TW, Kurz J, Doss MO, Fareed J. Singlet oxygen inactivates fibrinogen, factor V, factor VIII, factor X, and platelet aggregation of human blood. Thromb Res 2000;97:473-80. disrupts platelet aggregates. Thromb Res 2001;104:361-370. agonist-induced P-selectin expression and formation of platelet aggregates. Hemostasis Thrombosis Vascular Biol 2001;7:219-24. V. Platelet/polymorphonuclear leukocyte adhesion: a new role for SRC kinases in Mac-1 adhesive function triggered by P-selectin. Blood 2001;98:108-16. White LA, Brubaker LH, Aster RH, Henry PH, Adelstein EH. Platelet satellitism and phagocytosis by neutrophils: association with antiplatelet antibodies and lymphoma. American Journal of Hematology 1978;4:313-23.

61 Caccese D, Pratico D, Ghiselli A, Natoli S, Pignatelli P, Sanguigni V, Iuliano L, Violi F. Superoxide anion and hydroxyl radical release by collagen-induced platelet aggregation--role of arachidonic acid metabolism. Thromb Haemost 2000;83:485-90. 
Pratico D, Pasin M, Barry OP, Ghiselli A, Sabatino G, Iuliano L, FitzGerald GA, Violi F. Irondependent human platelet activation and hydroxyl radical formation: involvement of protein kinase C. Circulation 1999;99:3118-24.

63 Zielinski T, Wachowicz B, Saluk-Juszczak J, Kaca W. The Generation of Superoxide Anion in Blood Platelets in Response to Different Forms of Proteus mirabilis Lipopolysaccharide: Effects of Staurosporin, Wortmannin, and Indomethacin. Thromb Res 2001;103:149-55.

64 Seno T, Inoue N, Gao D, Okuda M, Sumi Y, Matsui K, Yamada S, Hirata K-i, Kawashima S, Tawa R, Imajoh-Ohmi S, Sakurai H, Yokoyama M. Involvement of NADH/NADPH Oxidase in Human Platelet ROS Production. Thromb Res 2001;103:399-409.

65 Levine PH, Weinger RS, Simon J, Scoon KL, Krinsky NI. Leukocyte-platelet interaction. Release of hydrogen peroxide by granulocytes as a modulator of platelet reactions. J Clin Invest 1976;57:955-63.

66 Koufos A, Sagone AL. Effects of oxidant stress on the hexose monophosphate shunt pathway of platelets. Blood 1980;55:835-40.

67 Canoso RT, Rodvien R, Scoon K, Levine PH. Hydrogen peroxide and platelet function. Blood $1974 ; 43: 645-56$.

Pratico D, Iuliano L, Alessandri C, Camastra C, Violi F. Polymorphonuclear leukocyte-derived O2-reactive species activate primed platelets in human whole blood. American Journal of Physiology 1993;264:H1582-7. hydrogen peroxide. J Immunol 1980;124:399-405. 


\section{TABLE HEADING AND LEGENDS TO FIGURES}

\section{Table 1.}

Effects of antibodies $(5 \mu \mathrm{g} / \mathrm{mL})$ and drugs against neutrophil and platelet surface receptors on the luminolamplified chemiluminescence in response to IgG-coated hydrophobic glass $(=$ control; $=100 \%)$. See "Materials and Methods" section for details. (N: receptors blocked on neutrophils; P: receptors blocked on platelets)

\section{Fig. 1.}

(A) Platelets amplify the IgG-triggered respiratory burst in neutrophils. Luminol-amplified chemiluminescence (CL) in neutrophils $\left(2 \times 10^{6} / \mathrm{mL}\right)$ under non-stirring conditions at $37^{\circ} \mathrm{C}$ for $30 \mathrm{~min}$ in IgG-, albumin- or non-coated coated hydrophobic glass tubes, with or without washed platelets $(1 \mathrm{x}$ $10^{8} / \mathrm{mL}$; added first). The results represent the mean integral values \pm SEM from 10 separate experiments with different donors $(n=10)$. The CL from platelets per se was negligible. All samples contained horseradish peroxidase (HRP; $4 \mathrm{U} / \mathrm{mL})$. Asterisks represent significant differences compared to neutrophils in non-coated tubes (CPM: counts per minute).

(B) Representative recordings showing the actual time course of CL (experimental conditions as in (A)).

(C) The total production of ROS measured in the presence of HRP. The intracellular ROS-generation was recorded by substituting HRP with superoxide dismutase (SOD, $200 \mathrm{U} / \mathrm{mL}$ ) and catalase (CAT, 2,000 $\mathrm{U} / \mathrm{mL})$. Experimental conditions as in (A).

Fig. 2 .

Disturbance of actin dynamics does not antagonize the platelet-mediated neutrophil chemiluminescence (CL) effects. Luminol-amplified CL under non-stirring conditions in IgG-coated hydrophobic glass tubes at $37^{\circ} \mathrm{C}$ with $4 \mathrm{U} / \mathrm{mL}$ horseradish peroxidase and $2 \times 10^{6} / \mathrm{mL}$ neutrophils in all samples. The neutrophil CLresponse in the presence of $1 \times 10^{8} / \mathrm{mL}$ platelets was transiently stimulated when $5 \mu \mathrm{M}$ jasplakinolide was introduced after approximately $15 \mathrm{~min}$. In comparison, the CR3-dependent CL-response of neutrophils 
triggered by complement-deposition from serum was abruptly inhibited by the addition of these drugs. When the cells were pre-incubated with jasplakinolide or cytochalasin B prior to surface-exposure the CLresponse was inhibited (not shown).

Fig. 3.

(A) The chemiluminescence (CL) was influenced by shear. Integrated values after 15 min of luminolamplified CL under stirring conditions $(700 \mathrm{rpm})$ in a two-sample Lumi-Aggregometer. The experiments were performed with washed platelets $\left(1 \times 10^{8} / \mathrm{mL}\right)$ and/or neutrophils $\left(2 \times 10^{6} / \mathrm{mL}\right)$ at $37^{\circ} \mathrm{C}$ in the presence of horseradish peroxidase $(4 \mathrm{U} / \mathrm{mL})$. The cells were stimulated after pre-warming with non-phagocytosable silicon particles $\left(1 \times 10^{5} / \mathrm{mL}\right)$ with or without covalently immobilized monolayers of $\operatorname{IgG}(n=13)$ or albumin $(n=4)$ on glutaraldehyde $(n=4)$. Asterisks represent significant differences compared to the albumin-triggered responses. (a.u.: arbitrary unit).

(B) Representative CL-trace in the IgG-coated particle system. Experimental conditions as in (A).

(C) As in (B), but with neutrophils stimulated by platelets that were pre-exposed to albumin- or IgGcoated particles for $5 \mathrm{~min}$ at $37^{\circ} \mathrm{C}$.

(D) As in (C), but shows the effect of filtration of the pre-stimulated platelet suspension through $0.22 \mu \mathrm{m}$ filters.

\section{Fig. 4.}

The effects of monoclonal antibodies on IgG-triggered ROS-production and aggregation in plateletneutrophil suspensions. Luminol-amplified chemiluminescence (A) and aggregation (B) were measured under stirring conditions in neutrophil/platelet mixtures (1/50 ratio) during stimulation with IgG-coated particles (as in Fig. 3). Neutrophils were pre-incubated for 10 min at $4^{\circ} \mathrm{C}$ with $5 \mu \mathrm{g} / \mathrm{mL}$ monoclonal antibodies that block PSGL-1 or L-selectin. Non-blocking control antibodies were W3/25 for anti-PSGL-1 and X 0931 for anti-L-selectin. Pre-incubation with anti-PSGL-1 inhibited the CL-response, whereas antibodies against L-selectin showed no effect. Anti-PSGL-1, anti-L-selectin or control antibodies did not inhibit IgG-induced cell aggregation. Asterisk represent significant difference compared to sample with control antibody $(n=5)$. 


\section{Fig. 5 .}

(A) Effect of protein coating on cell aggregation. Aggregation triggered by IgG-, albumin- or non-coated particles $\left(1 \times 10^{5} / \mathrm{mL}\right)$ in platelet $\left(1 \times 10^{8} / \mathrm{mL}\right)$ and/or neutrophil $\left(2 \times 10^{6} / \mathrm{mL}\right)$ suspensions at $37^{\circ} \mathrm{C}$ in a Lumi-Aggregometer with stirring set to $700 \mathrm{rpm}$. Average values after $15 \mathrm{~min} \pm \operatorname{SEM}(n=8)$. Asterisks represent significant differences compared to the albumin-triggered responses.

(B) Aggregation in platelet-suspensions measured as in (A), but also incorporating simultaneous assessment of platelet ATP-release by recording of integral luminescence values in the presence of luciferase $(176 \mathrm{U} / \mathrm{mL})$ and luciferin $(1.6 \mu \mathrm{g} / \mathrm{mL})$. (a.u.: arbitrary unit; $n=3$ ). Asterisk represent significant difference compared to the albumin-triggered response.

(C) Platelet and neutrophil aggregation during interaction with IgG-coated particles studied as in (A). Platelet aggregation depends on the presence of extracellular reactive oxygen species (ROS). Both intra- and extracellular ROS were generated in the presence of $4 \mathrm{U} / \mathrm{mL}$ horseradish peroxidase (HRP). Aggregation in the presence of only intracellulary generated ROS was obtained by substituting HRP for superoxide dismutase (SOD, $200 \mathrm{U} / \mathrm{mL}$ ) and catalase (CAT, 2,000 U/mL). CAT inhibited the IgGtriggered platelet aggregation, whereas SOD displayed the same results as HRP (not shown). $(n=4)$.

Fig. 6.

Surface-activated platelets support neutrophil binding. Mixed neutrophil/platelet suspensions were stimulated with covalently bound IgG on silicon particles. After 10 min of stimulation, the samples were fixed with $4 \%$ paraformaldehyde. The cells were permeabilized and filamentous actin stained with BODIPY $^{\circledR}$ FL phallacidin and platelet CD41 stained with R-phycoerythrin-conjugated monoclonal antiCD41. The slides were excited by blue (A) and green (B) fluorescence light or observed in light microscopy mode (C). Neutrophils and platelets bound to and spread at IgG-coated particles, but only to a minor extent at albumin-coated particles. Neutrophils could not phagocytose any of the particles. Platelets were almost always present between the particle surfaces and adhered neutrophils. $(\mathrm{Bar}=10 \mu \mathrm{m})$. 


\section{Fig. 7.}

Formation of aggregates of neutrophils, platelets and platelet fragments/microparticles after stimulation with IgG-coated particles. Cells were paraformaldehyde-fixed after $10 \mathrm{~min}$ of interaction with IgGparticles, permeabilized and stained for filamentous actin (in both neutrophils and platelets) with BODIPY ${ }^{\circledR}$ FL phallacidin (A) and platelet CD41 with R-phycoerythrin-conjugated monoclonal anti-CD41 (B). Figure shows the same cells excited by blue (A) or green (B) fluorescence light. Aggregates were present in large numbers after stimulation with IgG-coated particles, but only occasionally after interaction with albumincoated particles (not shown). (Bar $=10 \mu \mathrm{m})$.

\section{Fig. 8.}

Contact-dependent platelet-neutrophil interaction. The platelets were exposed to IgG-coated silicon particles for $5 \mathrm{~min}$, followed by sedimentation of the particles and collection of the platelet fraction for stimulation of neutrophils during $10 \mathrm{~min}$. Samples were then paraformaldehyde-fixed, permeabilized and stained for filamentous actin (in both neutrophils and platelets) with BODIPY ${ }^{\circledR}$ FL phallacidin (A) and platelet CD41 was stained with R-phycoerythrin-conjugated monoclonal anti-CD41 (B). Figure shows the same slide excited by blue (A) or green (B) fluorescence light. Most neutrophils were found in large neutrophil-platelet aggregates (as shown in Fig. 6) or as shown here with a few surface-associated platelets. No solitary neutrophils were observed. (Bar $=10 \mu \mathrm{m})$. 


\section{Table 1:}

\begin{tabular}{lcc}
\hline & Inhibition (\% of control) & Stimulation (\% of control) \\
\hline Anti-FcRIII (N) & $21 \%$ & \\
Anti-FcRIII (N) & $18 \%$ & \\
Anti-FcRII and III (N) & $29 \%$ & \\
Anti-FcRII (P) & $29 \%$ & \\
Dextransulfate $(0.4 \mathrm{mg} / \mathrm{mL})$ & $81 \%$ & $6 \%$ \\
Anti-L-selectin & & \\
Anti-PSGL-1 & $21 \%$ & \\
Anti-P-selectin & $23 \%$ & $10 \%$ \\
P1-peptide $(100 \mu \mathrm{M})$ & & $1 \%$ \\
Echistatin $(0.1 \mu \mathrm{M})$ & & $11 \%$ \\
RGDS $(0.1 \mathrm{mg} / \mathrm{mL})$ & & \\
\hline
\end{tabular}


Figure 1A:

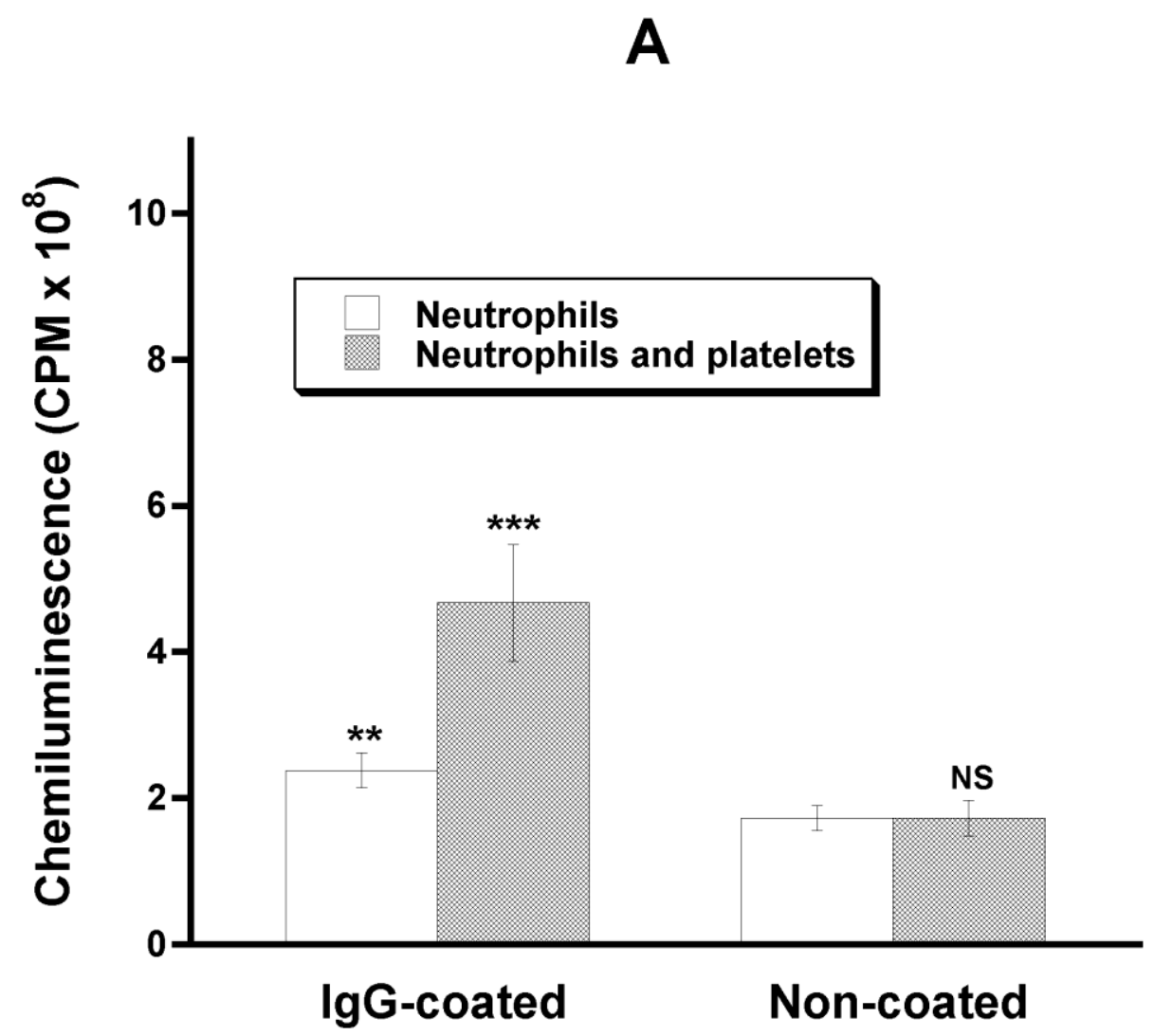




\section{Figure 1B:}

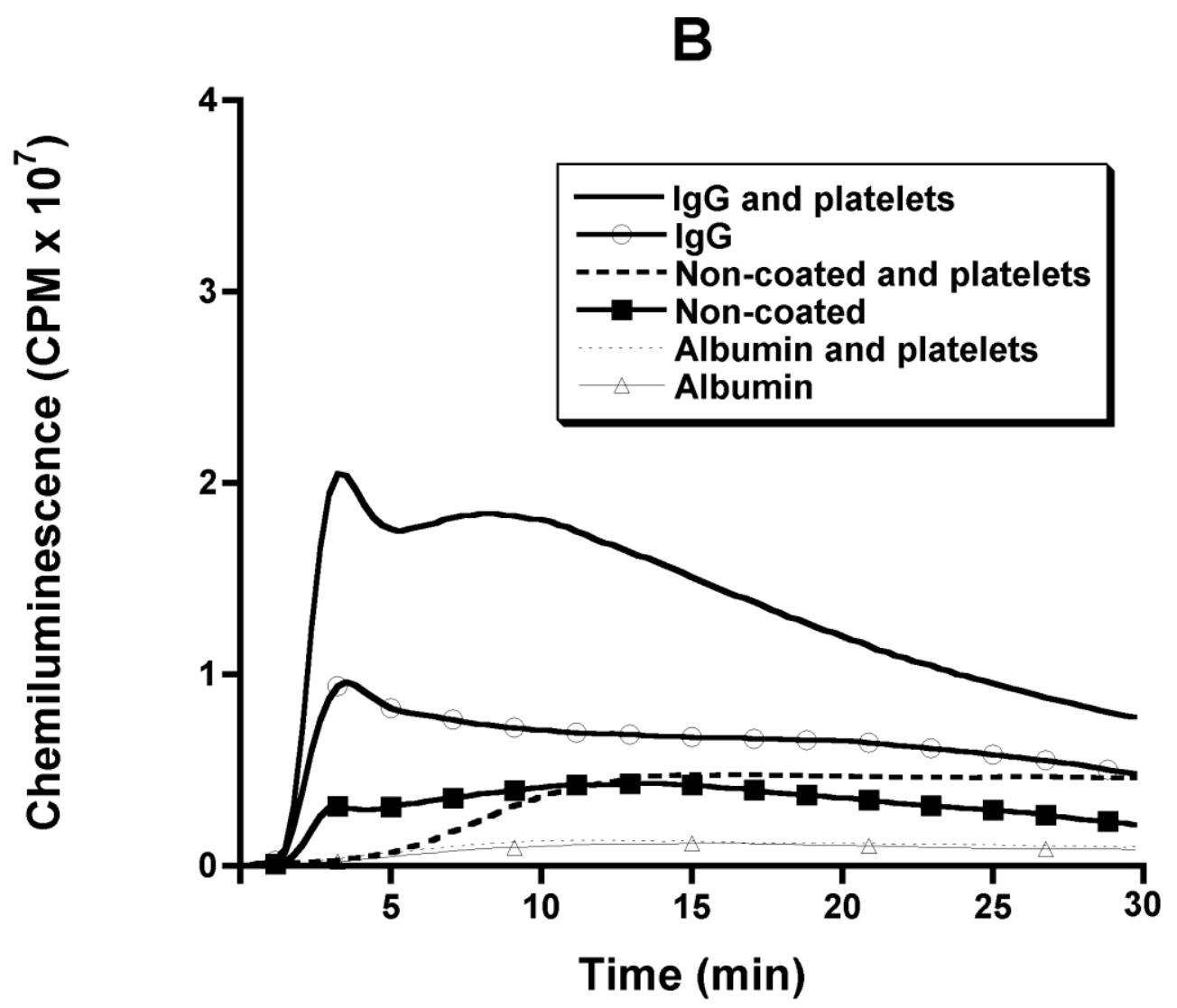




\section{Figure 1C}

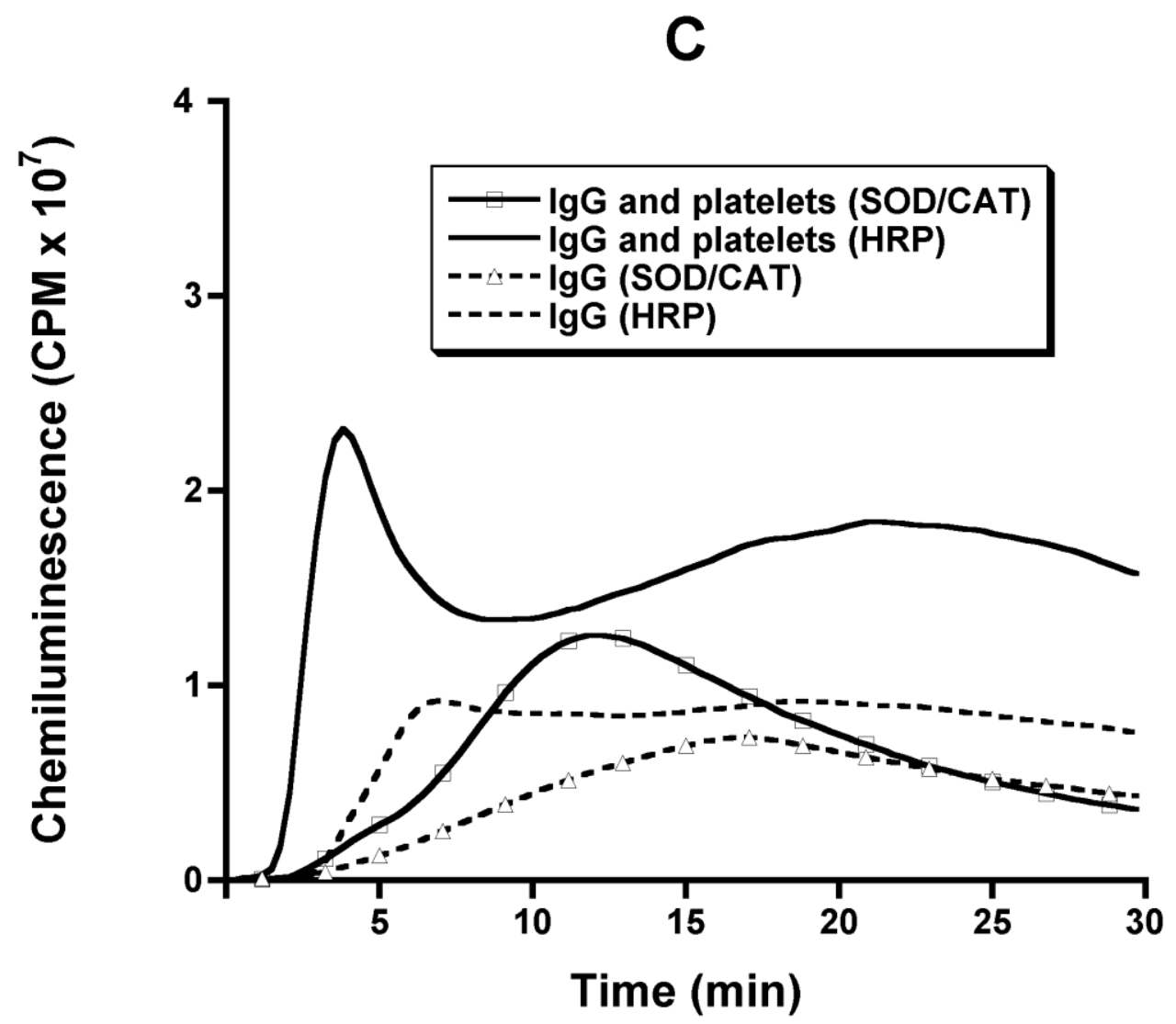


Figure 2

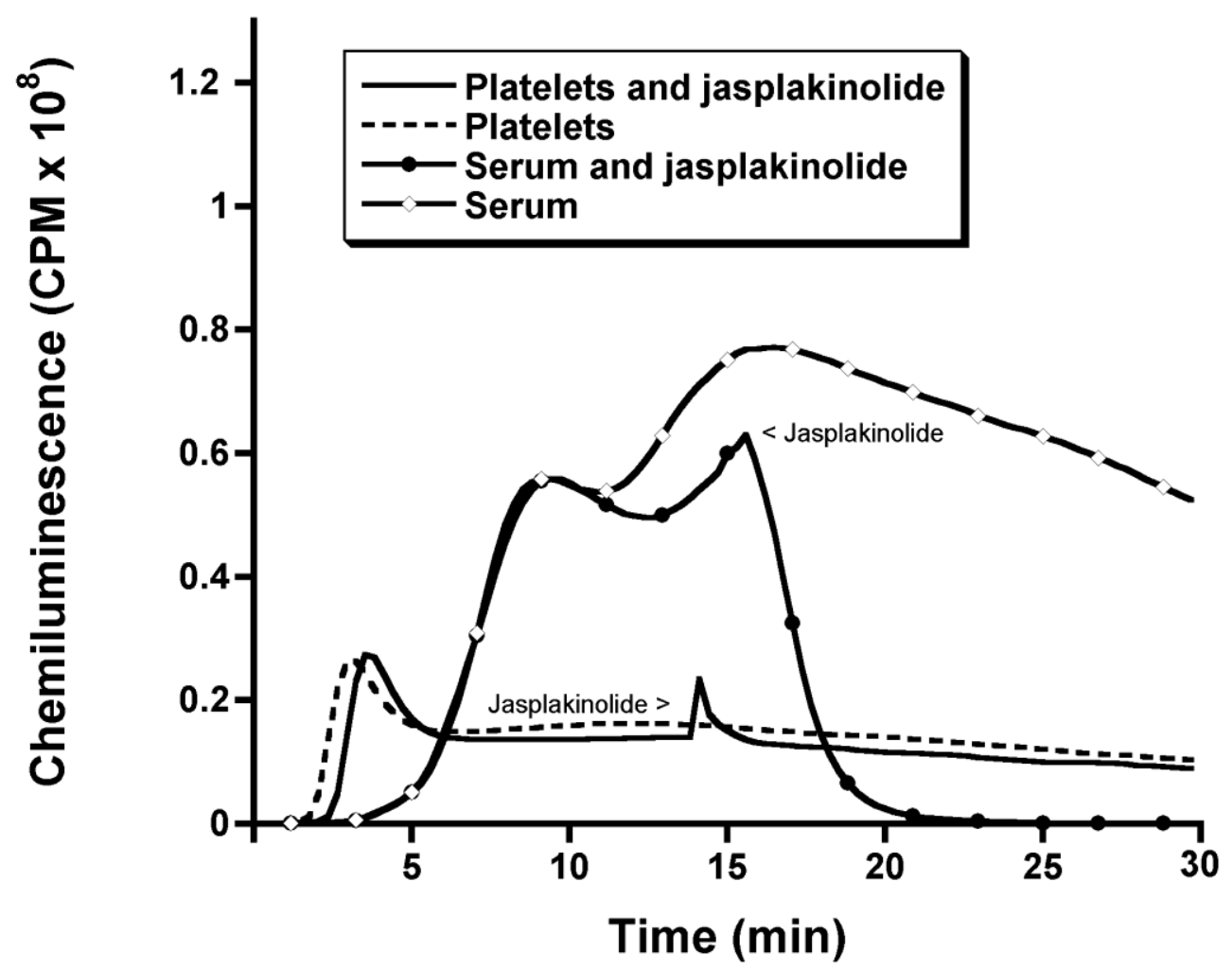


Figure 3A

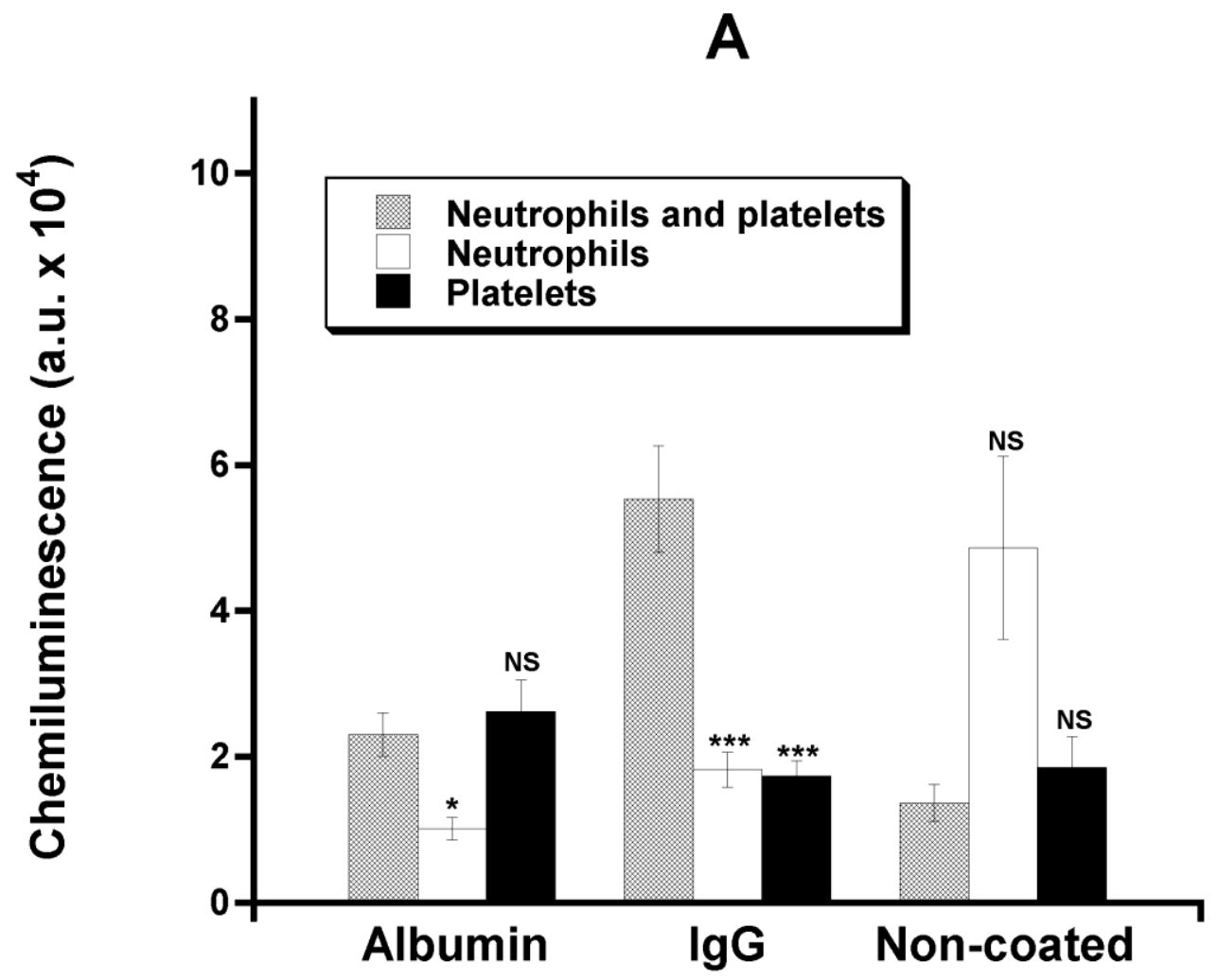




\section{Figure 3B}

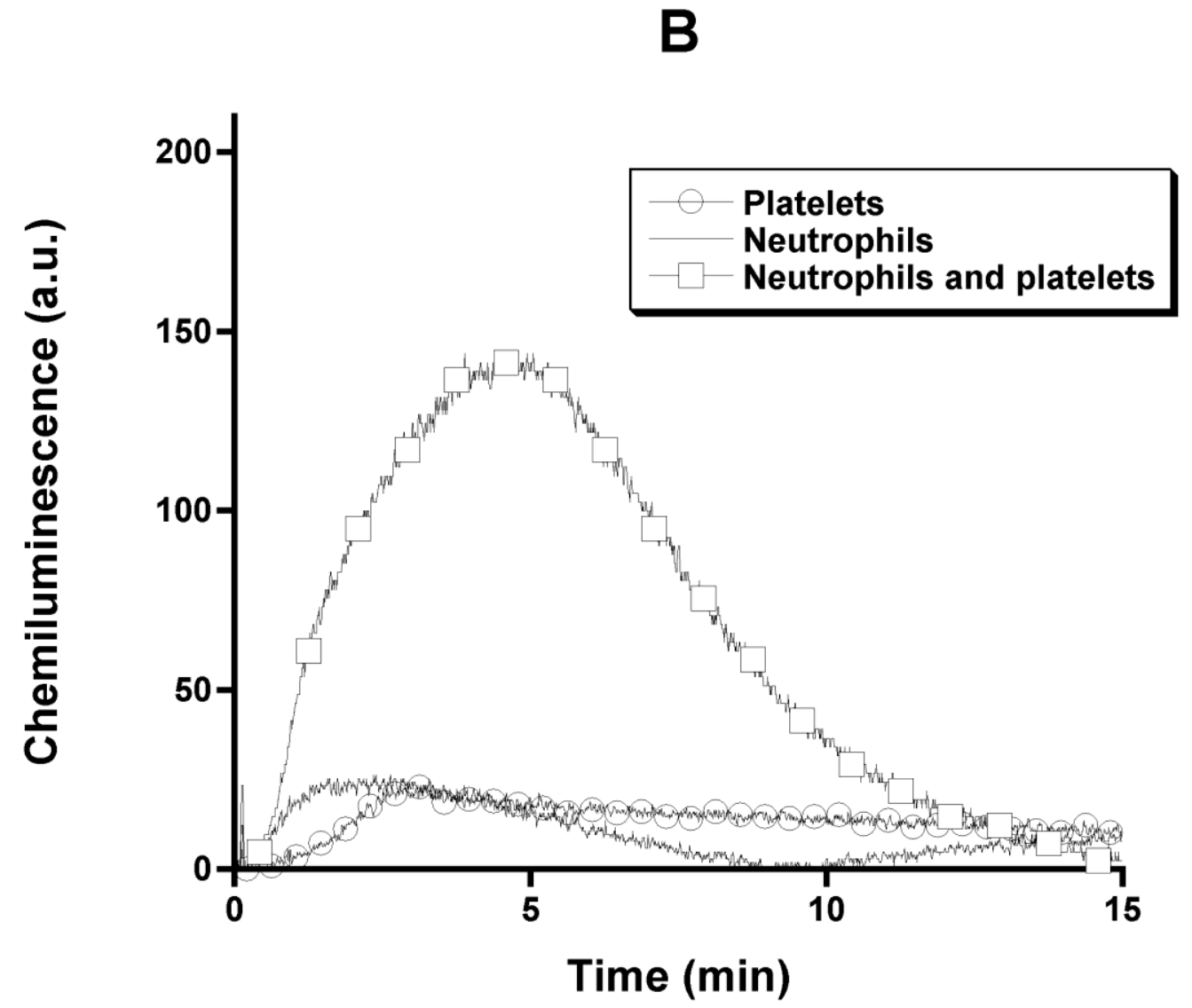


Figure 3C

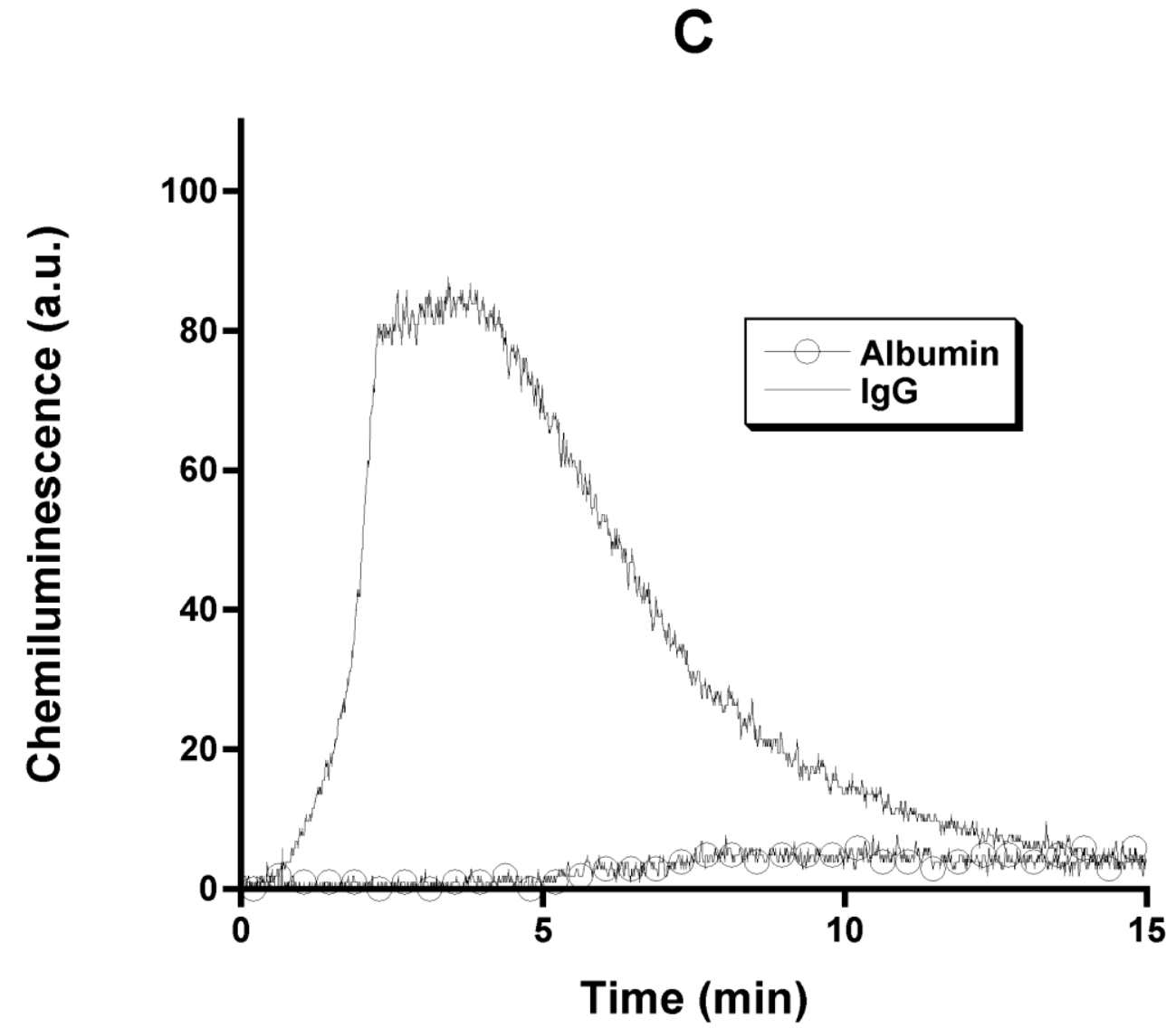


Figure 3D

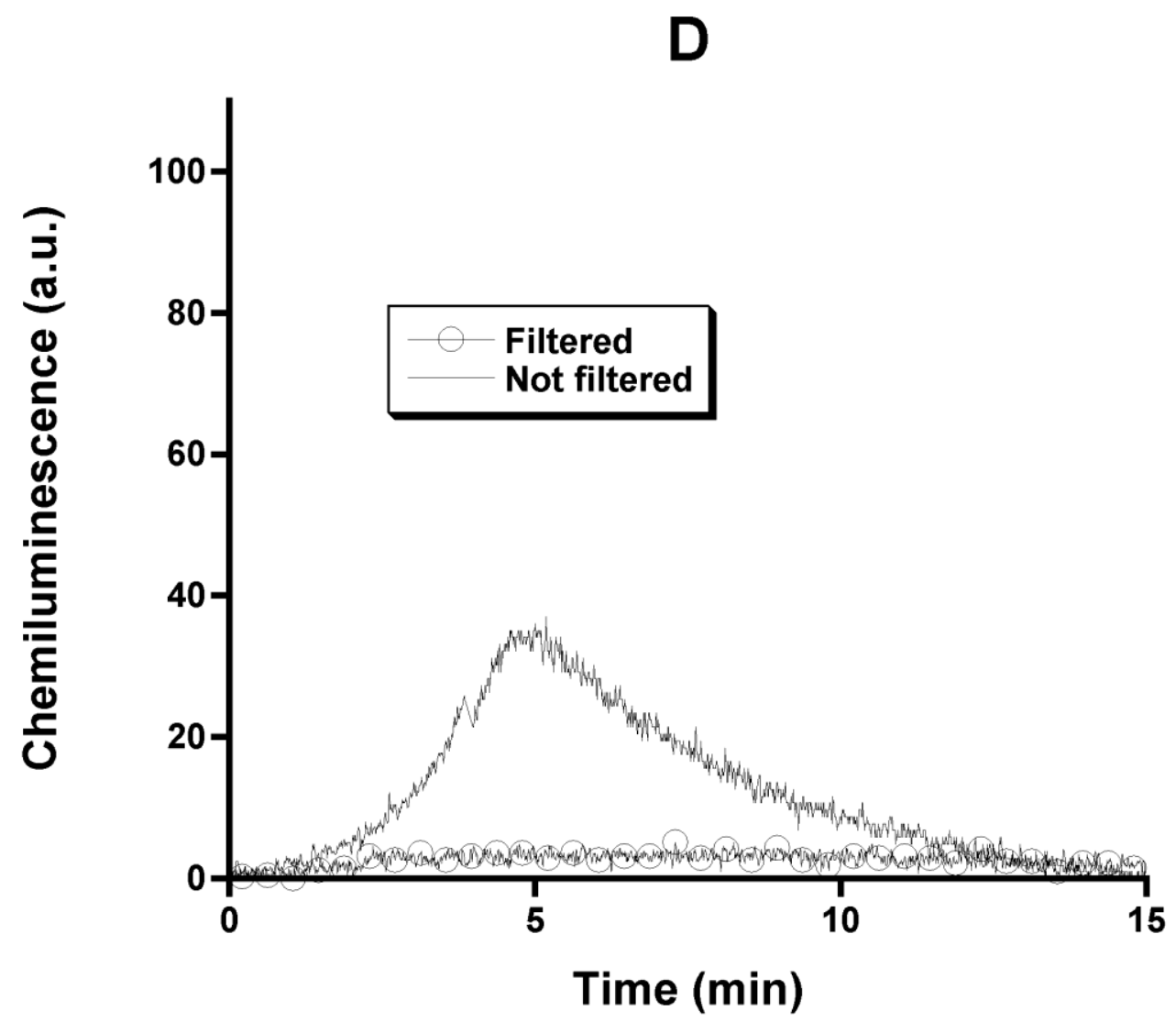


Figure 4A

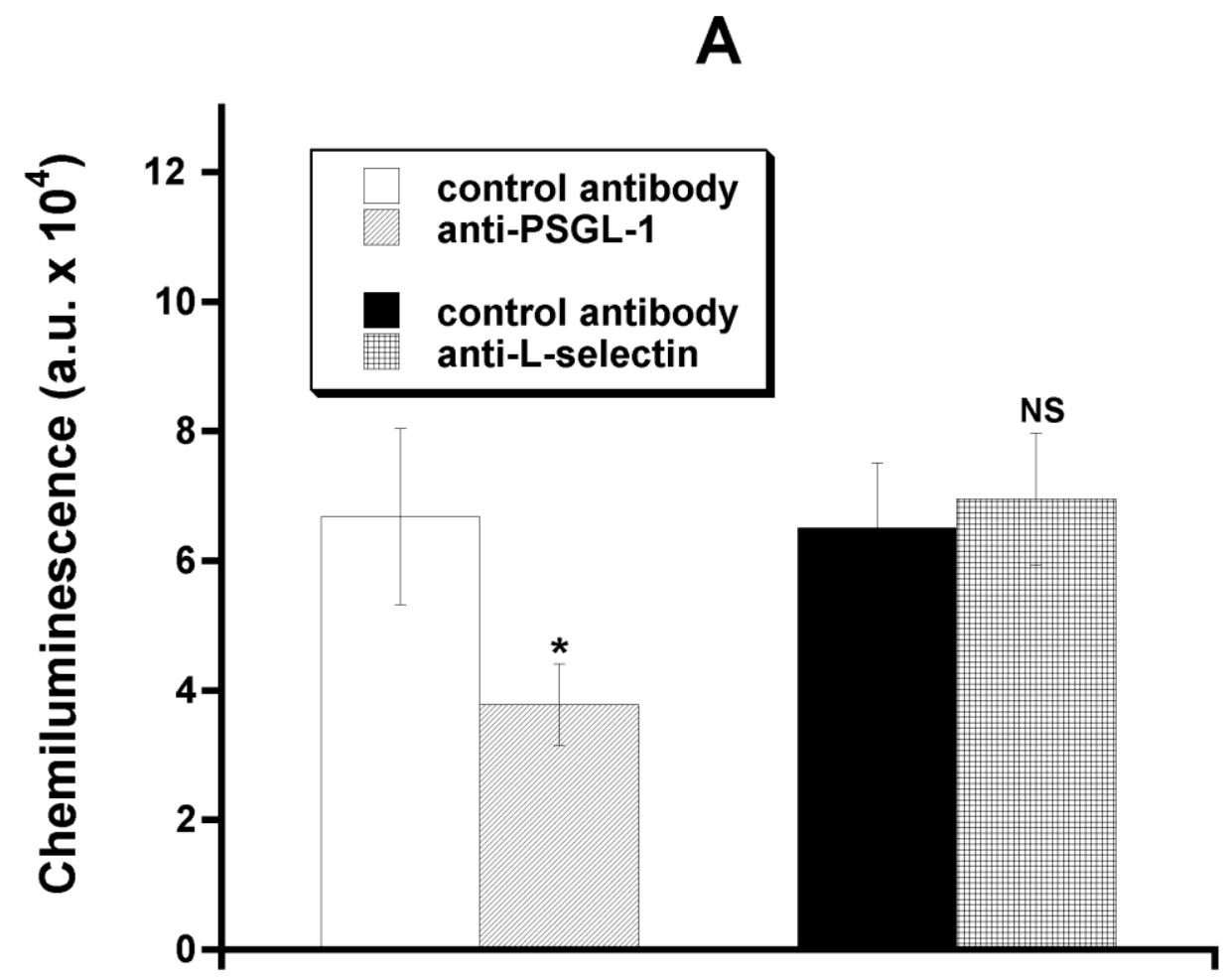




\section{Figure 4B}

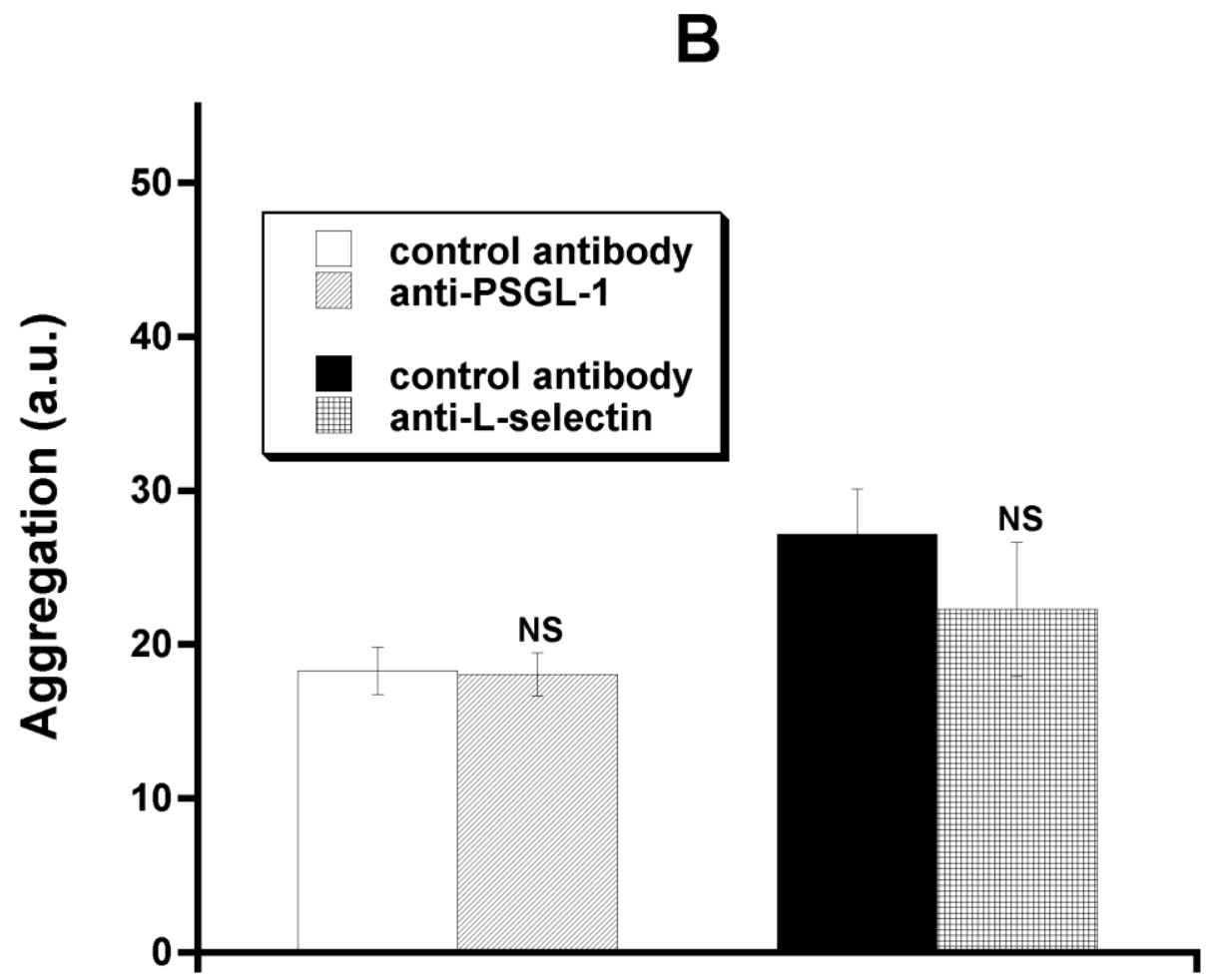


Figure 5A

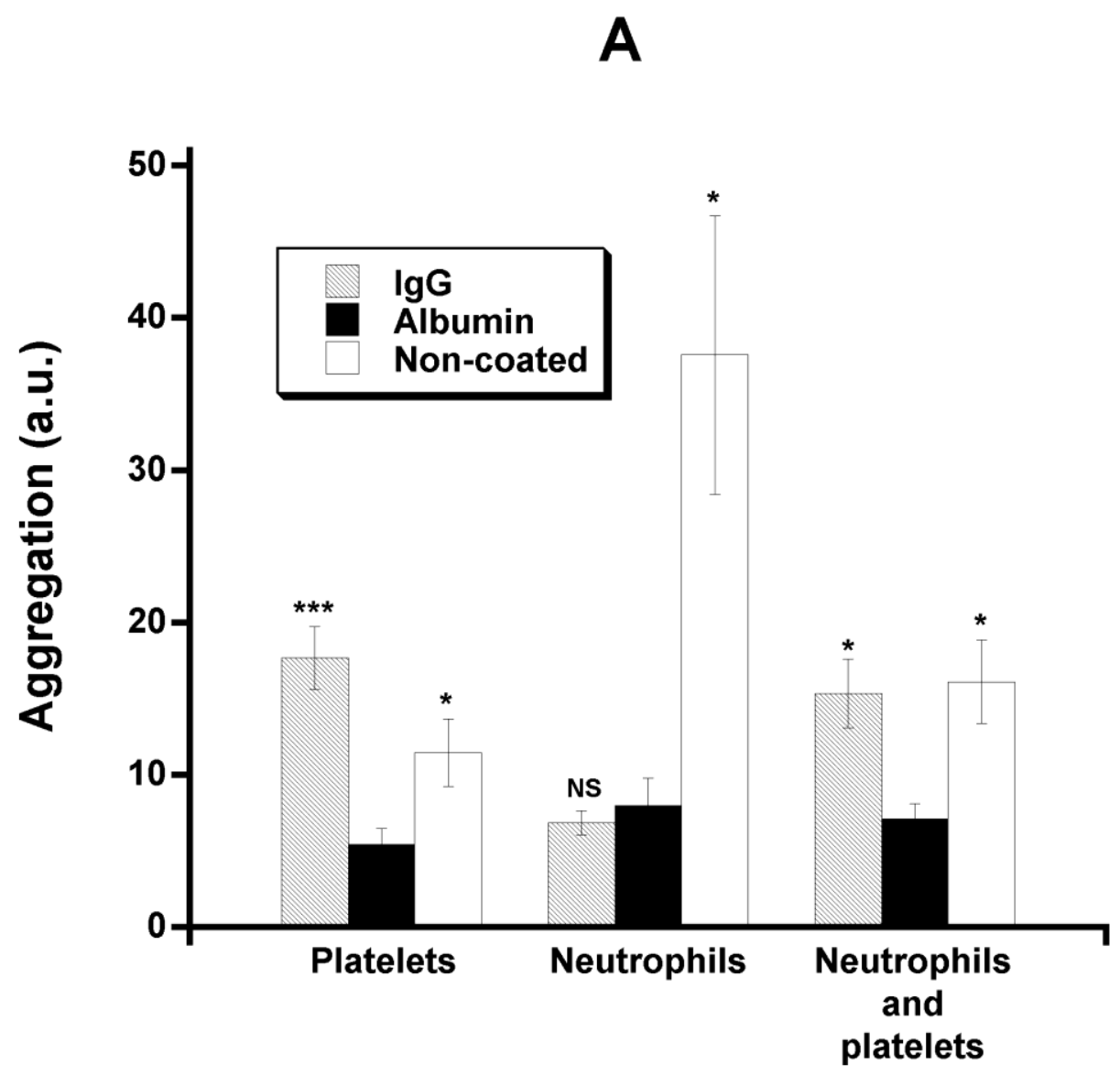




\section{Figure 5B}

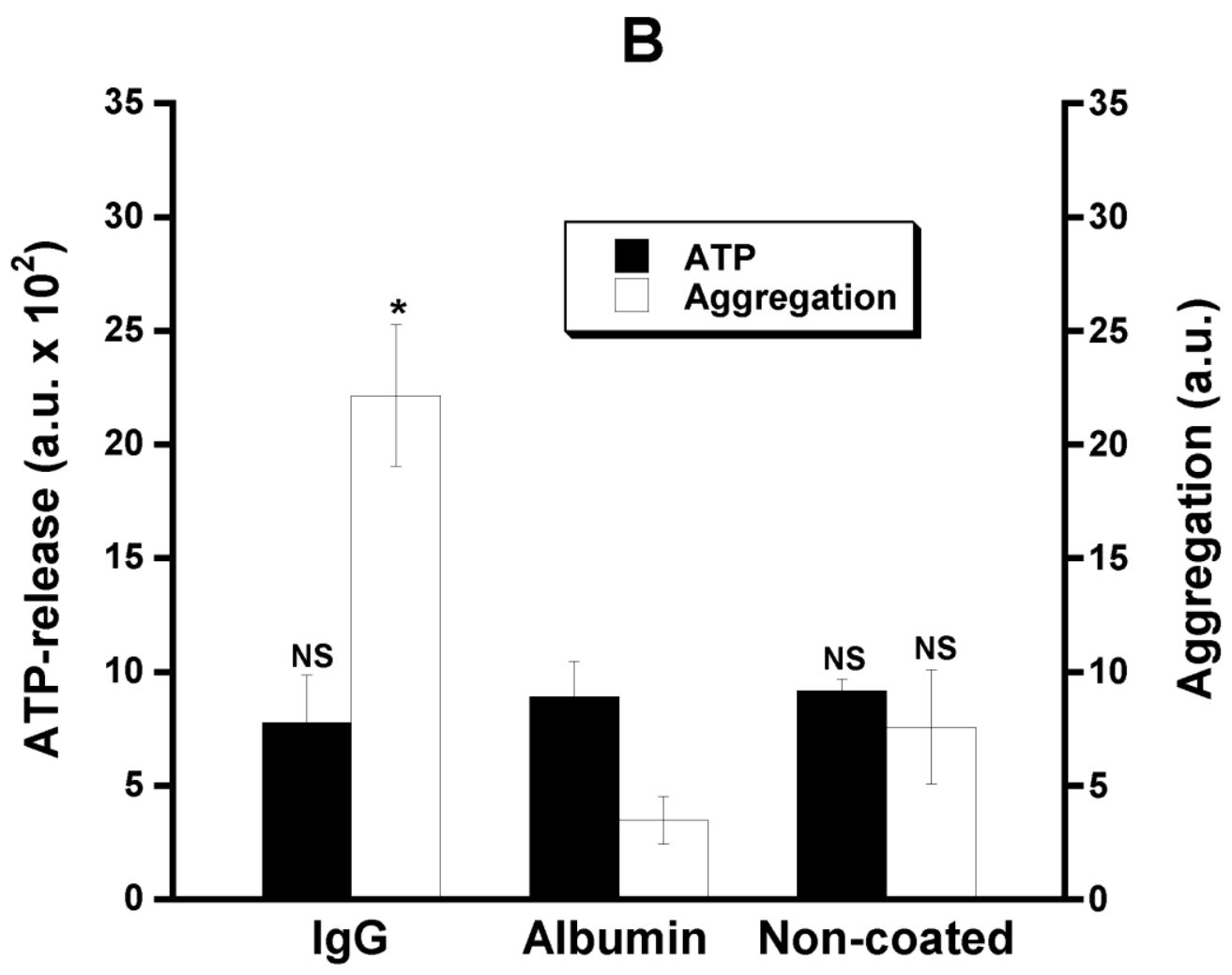


Figure 5C

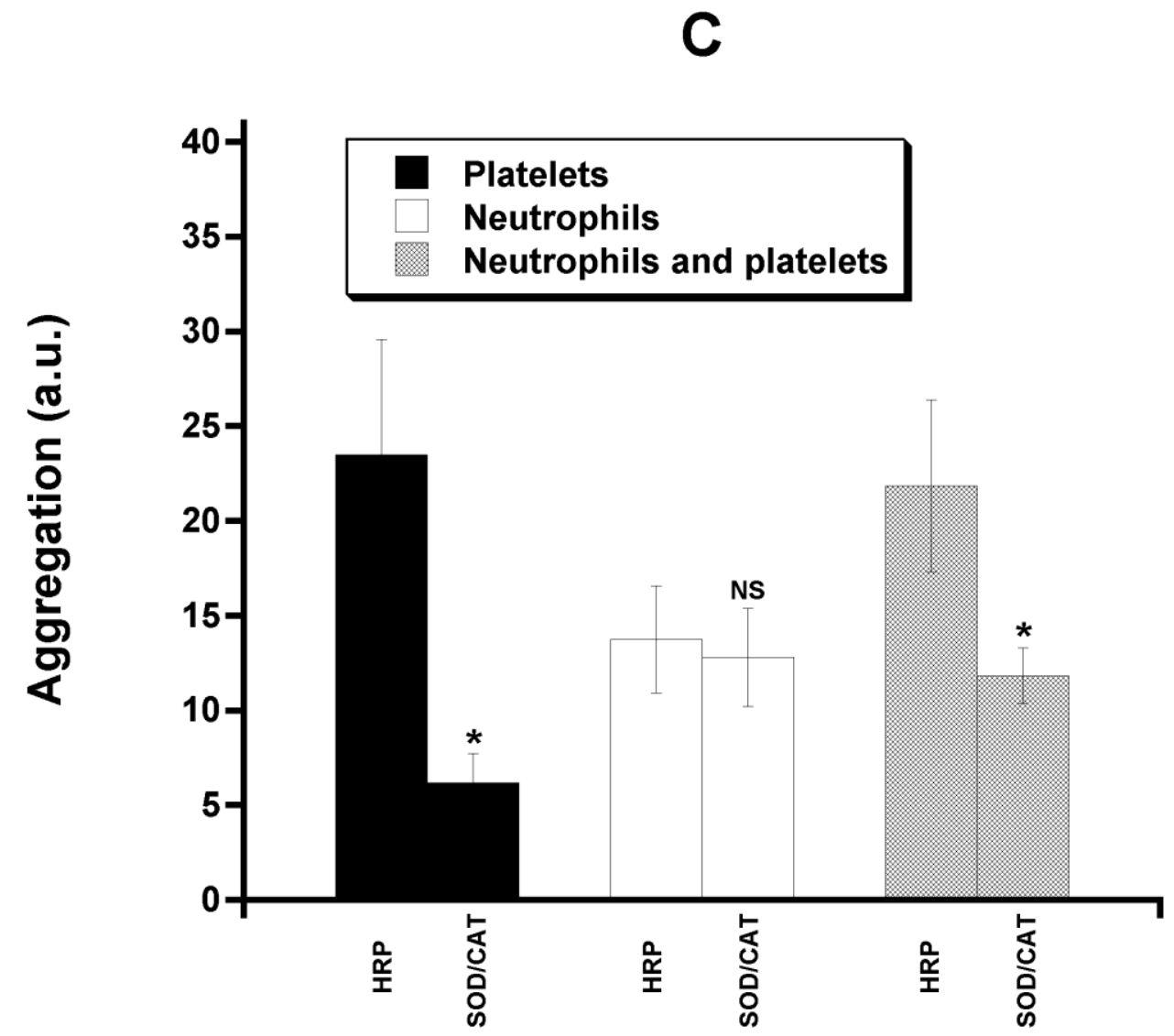


Figure 6 (in color!)
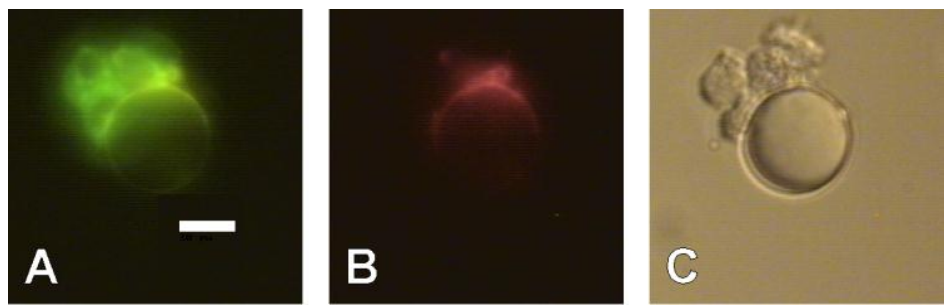


\section{Figure 7 (in color!)}
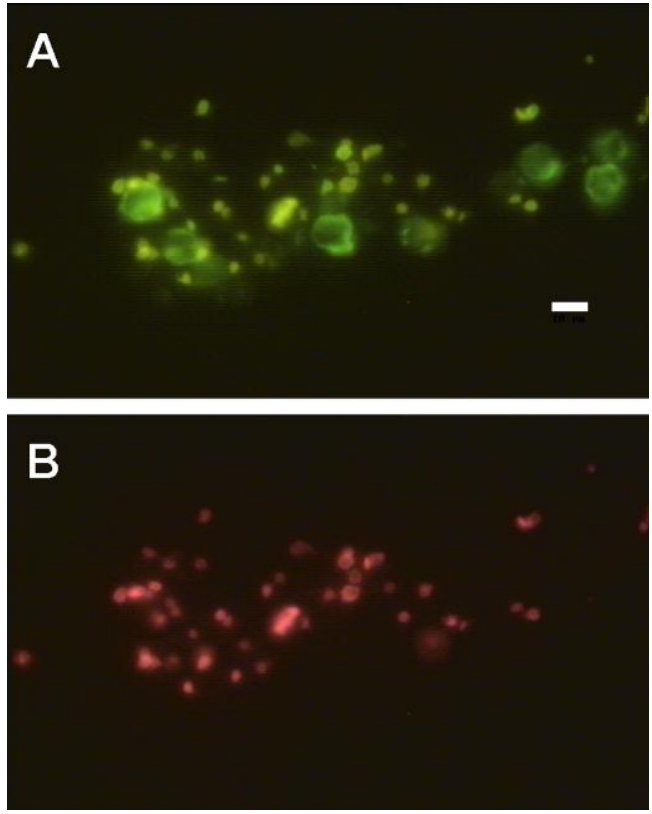


\section{Figure 8 (in color!)}

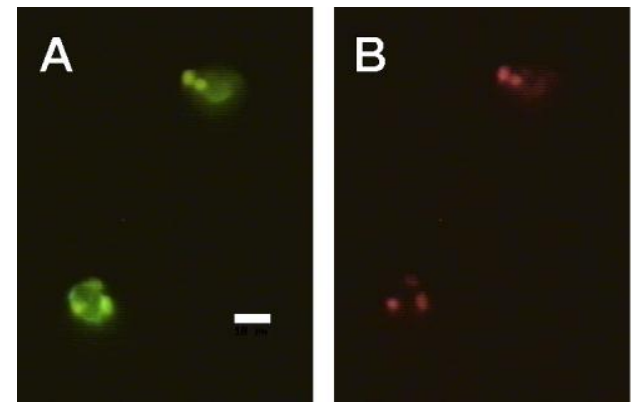

